\title{
Lusioersily
}

\section{Biochemical mechanisms of aggregation in TGFBI-linked corneal dystrophies}

Nielsen, N. S., Toftgaard Poulsen, E., Lukassen, M. V., Chao Shern, C., Hage Mogensen, E., Weberskov, C. E., Dedionisio, L., Schauser, L., Moore, T. C. B., Otzen, D. E., Hjortdal, J., \& Enghild, J. J. (2020). Biochemical mechanisms of aggregation in TGFBI-linked corneal dystrophies. Progress in Retinal and Eye Research, 77, [100843]. https://doi.org/10.1016/j.preteyeres.2020.100843

Link to publication record in Ulster University Research Portal

\section{Published in:}

Progress in Retinal and Eye Research

Publication Status:

Published (in print/issue): 31/07/2020

DOI:

10.1016/j.preteyeres.2020.100843

\section{Document Version}

Author Accepted version

\section{General rights}

Copyright for the publications made accessible via Ulster University's Research Portal is retained by the author(s) and / or other copyright owners and it is a condition of accessing these publications that users recognise and abide by the legal requirements associated with these rights.

\section{Take down policy}

The Research Portal is Ulster University's institutional repository that provides access to Ulster's research outputs. Every effort has been made to ensure that content in the Research Portal does not infringe any person's rights, or applicable UK laws. If you discover content in the Research Portal that you believe breaches copyright or violates any law, please contact pure-support@ulster.ac.uk. 


\section{Biochemical mechanisms of aggregation in TGFBI-linked corneal dystrophies}

Nadia Sukusu Nielsen ${ }^{a}$, Ebbe Toftgaard Poulsen ${ }^{a}$, Marie V. Lukassen ${ }^{b}$, Connie Chao Shern ${ }^{c, d}$, Emilie Hage Mogensen ${ }^{a}$, Christian E. Weberskov ${ }^{a}$, Larry DeDionisio ${ }^{d}$, Leif Schauser ${ }^{e}$, Tara C. B. Moore ${ }^{c, d}$, Daniel E. Otzen ${ }^{a, f}$, Jesper Hjortdal ${ }^{\mathrm{a}}$, Jan J. Enghild ${ }^{\mathrm{a}, *}$

${ }^{a}$ Department of Molecular Biology and Genetics, Aarhus University, Aarhus, Denmark

${ }^{\mathrm{b}}$ Biomolecular Mass Spectrometry and Proteomics, Utrecht Institute for Pharmaceutical Sciences, University of Utrecht, Utrecht, the Netherlands

'Biomedical Sciences Research Institute, Ulster University, Coleraine, Northern Ireland, UK

${ }^{d}$ Avellino Labs USA, Menlo Park, USA

${ }^{e}$ QIAGEN Aarhus A/S, Aarhus, Denmark

${ }^{f}$ Interdisciplinary Nanoscience Centre (iNANO), Aarhus University, Aarhus, Denmark

${ }^{\mathrm{g}}$ Department of Ophthalmology, Aarhus University Hospital, Aarhus, Denmark

* Corresponding author. Department of Molecular Biology and Genetics, Aarhus University, Gustav Wieds vej 10C, Aarhus, Denmark.E-mail: jje@mbg.au.dk

\section{Author contributions (\%)}

The percentage of work contributed by each author in the production of the manuscript is as follows: NSN $25 \%$, ETP 10\%, MVL 10\%, CCS 5\%, EHM 2\%, CEW 2\%, LD 2\%, LS 4\%, TCBM 5\%, DEO 10\%, JH 10\%, and JJE 15\%. 


\section{ABSTRACT}

Transforming growth factor- $\beta$-induced protein (TGFBIp), an extracellular matrix protein, is the second most abundant protein in the corneal stroma. In this review, we summarize the current knowledge concerning the expression, molecular structure, binding partners, and functions of human TGFBIp. To date, 74 mutations in the transforming growth factor- $\beta$-induced gene (TGFBI) are associated with amyloid and amorphous protein deposition in TGFBI-linked corneal dystrophies. We discuss the current understanding of the biochemical mechanisms of TGFBI-linked corneal dystrophies and propose that mutations leading to granular corneal dystrophy (GCD) decrease the solubility of TGFBIp and affect the interactions between TGFBIp and components of the corneal stroma, whereas mutations associated with lattice corneal dystrophy (LCD) lead to a destabilization of the protein that disrupts proteolytic turnover, especially by the serine protease HtrA1. Future research should focus on TGFBlp function in the cornea, confirmation of the biochemical mechanisms in vivo, and the development of disease models. Future therapies for TGFBI-linked corneal dystrophies might include topical agents that regulate protein aggregation or gene therapy that targets the mutant allele by CRISPR/Cas9 technology.

Keywords: human cornea, corneal dystrophies, protein aggregation, TGFBI gene, TGFBIp, CRISPR/Cas9

Abbreviations: Cas9, CRISPR-associated protein 9; CRISPR, clustered regularly interspaced short palindromic repeats; CROPT, cysteine-rich domain of periostin and TGFBIp; DALK, deep anterior lamellar keratoplasty; ECM, extracellular matrix; FAS1, fasciclin 1; GAG, glycosaminoglycan; GCD1, granular corneal dystrophy type 1; GCD2, granular corneal dystrophy type 2; HtrA1, high-temperature requirement A1; LASIK, laser-assisted in situ keratomileusis; LCD1, lattice corneal dystrophy type 1; PAM, protospacer adjacent motif; PK, penetrating keratoplasty; PTK, phototherapeutic keratectomy, PTM, posttranslational modification; RBCD, Reis-Bücklers corneal dystrophy; SALK, superficial anterior lamellar keratoplasty; SAP, serum amyloid P; SNP, single nucleotide polymorphism; TBCD, Thiel-Behnke corneal dystrophy; TGFBI, transforming growth factor- $\beta$-induced gene; TGFBIp, transforming growth factor- $\beta$-induced protein 


\section{Contents}

1. TGFBIp

1.1. Expression of TGFBIp

1.1.1. TGFBIp is widely expressed in human tissues

1.1.2. Corneal TGFBIp expression.

1.2. Structural organization of TGFBIp

1.2.1. Primary sequence of TGFBIp

1.2.2. Secondary and tertiary structure of TGFBIp

1.2.3. Quaternary structure of TGFBIp

1.2.4. What can be learned from the structure of periostin?

1.3. Protein interactions of TGFBIp

\subsubsection{Integrins}

1.3.2. Extracellular matrix proteins

1.3.3. Collagens

1.4. Physiological function of TGFBIp

1.5. TGFBIp in diseases

1.5.1. Roles in cancer

1.5.2. Diseases of the cornea

2. TGFBI-linked corneal dystrophies

2.1. Definition and classification

2.2. Socioeconomic burden and quality of life

2.2.1. Symptoms

2.2.2. Epidemiology

2.2.3. Genetic testing before vision correction

2.3. The R124 and R555 hotspots are highly mutable

3. Biochemical mechanisms of TGFBI-linked corneal dystrophies

3.1. Proteomic profiling of deposits

3.1.1. Protein profiles of GCD deposits

3.1.2. Protein profiles of $L C D$ deposits

3.2. Proteolytic processing

3.2.1. Tissue-specific processing of TGFBIp

3.2.2. HtrA1 proteolysis in LCD

3.3. The FAS1-4 domain mimics many properties of full-length TGFBIp, making it an excellent model system 
3.4. A comprehensive mutagenic and bioinformatics study highlights fundamental differences between LCD and GCD mutants

3.5. Impact of glycosaminoglycans on fibrillation mechanisms

3.6. Proposed mechanisms of action in TGFBI-linked corneal dystrophies

4. Treatment strategies

4.1. Current treatment options

4.1.1. Keratectomy

4.1.2. Corneal transplantation

4.1.3. Staged treatment of TGFBI-linked corneal dystrophies

4.2. Animal models

4.2.1. Current TGFBI mouse models

4.2.1.1. Knockout mouse models

4.2.1.2. Overexpression mouse models

4.2.1.3. TGFBI mutant mouse models

4.2.2. Future directions for $T G F B I$ animal model generation

4.3. Future treatment options

4.3.1. The use of CRISPR/Cas9 for the treatment of inherited disease

4.3.2. CRISPR/Cas9 gene editing for TGFBI-linked corneal dystrophies

4.3.2.1. Corneal autosomal dominant genetic eye disease - allele specificity

4.3.2.2. Mutant allele targeting, a dual cut approach

4.3.3. Anti-fibrillating agents

5. Future directions and conclusions

Disclosure

Acknowledgments

References

Tables

Figure legends

Figures 


\section{TGFBIp}

\subsection{Expression of TGFBIp}

\subsubsection{TGFBIp is widely expressed in human tissues}

The transforming growth factor- $\beta$-induced gene (TGFBI), originally named $\beta i g-h 3$, is a 34,924-nucleotide transcript containing 17 exons that, after processing, becomes a 2,052-nucleotide protein-coding sequence. The gene was discovered by Skonier et al. in a human lung adenocarcinoma cell line following addition of the pleiotropic cytokine TGF- $\beta 1$ (Skonier et al., 1992). The gene was designated $\beta i g-h 3$ (TGF- $\beta 1$-induced-gene-human, clone 3) (GenBank accession number M77349), and its mRNA was increased up to 20-fold in this cell line after two days of treatment with TGF- $\beta 1$. TGFBI mRNA encodes the highly conserved transforming growth factor- $\beta$-induced protein TGFBIp. In subsequent studies, TGFBIp was also named MP78/70 (Gibson et al., 1997), collagen fiber-associated protein (RGD-CAP) (Hashimoto et al., 1997), and kerato-epithelin (Munier et al., 1997). TGFBI is widely expressed in various organs and tissues throughout the body, such as the heart, breast, testes, prostate, intestines, skin, ovary, liver, pancreas, lung, leukocytes, placenta, and kidney (Ivanov et al., 2008; Skonier et al., 1992). In 1994, it was shown that TGFBIp is a major protein in the human cornea (Klintworth et al., 1994).

\subsubsection{Corneal TGFBIp expression}

TGFBIp is the second most abundant protein in the human corneal stroma and is present in all of the corneal layers (Dyrlund et al., 2012). The expression of TGFBIp increases by $30 \%$ during the first to second decade of life (Karring et al., 2010). It is a common perception that the majority of corneal TGFBIp is expressed in the epithelium (Escribano et al., 1994). Recently, this perception was supported by in situ hybridization analysis in mice, demonstrating that TGFBI mRNA was restricted to the corneal epithelium (Poulsen et al., 2018). However, in humans, TGFBIp is also expressed by keratocytes, particularly in the peripheral corneal stroma (Liu et al., 2017). We estimated the concentration of TGFBIp in the human cornea using a quantitative western blotting protocol (unpublished data). Human postmortem corneas from three individuals (two females and one male at the age of 81-91 years) were acquired, and well-defined plugs with a diameter of $2 \mathrm{~mm}$ were generated from the central cornea. Assuming a thickness of $0.5 \mathrm{~mm}$, the volume of the corneal plugs was $1.73 \mu \mathrm{l}$. The plugs were boiled in denaturing buffer under reducing conditions, and the extracted protein was separated by polyacrylamide gel electrophoresis along with a known concentration of recombinant TGFBIp. The proteins were transferred to a membrane followed by immunoblotting with an anti-TGFBlp antibody. A titration curve of recombinant TGFBlp was used to calculate the amount of TGFBIp in the corneal plug from each of the three individuals. The average concentration of human TGFBlp in the central cornea was estimated to be $26.4 \mu \mathrm{M}( \pm 4.6)$. The high concentration of TGFBIp in the cornea collaborates with our previous study on the human corneal proteome in which TGFBIp 
appeared as the second most and most abundant protein in the stroma and endothelium (Dyrlund et al., 2012). Disregarding collagen type 1 in the stroma, the relative molar fraction of TGFBIp was at least three and six times higher than other corneal proteins in the stroma and endothelium, respectively.

\subsection{Structural organization of TGFBIp}

\subsubsection{Primary sequence of TGFBIp}

TGFBIp is composed of 683 residues, including an $\mathrm{N}$-terminal secretory signal peptide of 23 residues. The protein consists of an N-terminal cysteine-rich domain of periostin and IGFBIp (CROPT) domain followed by four fasciclin 1 (FAS1) domains (FAS1-1, FAS1-2, FAS1-3, and FAS1-4) (Fig. 1A). The CROPT domain contains six of the 11 cysteine residues in TGFBIp and has previously been described as an EMI domain due to sequence similarities (Doliana et al., 2000). However, multiple sequence alignment revealed a 29-residue-long deletion, misalignment of two conserved cysteine residues, and a four-residue insertion into the EMI consensus motif (Lukassen et al., 2016). These observations alongside structural features, which will be discussed in sections 1.2.2 and 1.2.4, caused us to rename the N-terminal EMI domain to CROPT (García-Castellanos et al., 2017). The FAS1 domains are followed by a C-terminal region (residues 633-683) that contains an RGD integrin-binding motif. Most of the human corneal TGFBIp is truncated at A657, just three residues downstream of the RGD motif. It is currently unknown whether this proteolytic event occurs before or after secretion, but its proximity to the RGD motif indicates that it participates in regulating the cell binding properties of TGFBIp (Andersen et al., 2004). Analysis of corneal extracts by two-dimensional gel electrophoresis followed by immunoblotting revealed several TGFBIp isoforms with a molecular weight in the 30-60 kDa range and an isoelectric point between 5.5 and 6.2, forming a "zigzag" pattern (Karring et al., 2010). Mass spectrometry analysis revealed that all the isoforms were $\mathrm{N}$-terminal truncated versions of the mature protein lacking 210-375 residues corresponding to the CROPT, FAS1-1, and FAS1-2 domains. The proteolytic processing of TGFBIp will be described in detail in section 3.2.

TGFBIp purified from corneal extracts did not show any evidence for posttranslational modifications (PTMs) (Andersen et al., 2004), but other studies have identified phosphorylation at S37 (Bian et al., 2014; Srivastava and Srivastava, 1999). Gamma-carboxylation has also been suggested as a PTM, but this observation is controversial and has been disputed by others (Annis et al., 2015; Coutu et al., 2008). Five disulfide bridges in TGFBlp have been identified, of which three are intradomain bridges located in the CROPT domain (C49-C85 and C84-C97) and the FAS1-3 domain (C473-C478) (Lukassen et al., 2016) (Fig. 1A). The remaining disulfide bridges connect the CROPT domain to the FAS1-2 domain (C74-C339) and the FAS1-1 domain to the FAS1-2 domain (C214-C317). The last cysteine residue located in the CROPT domain (C65) was modified by cysteinylation.

\subsubsection{Secondary and tertiary structure of TGFBIp}


The crystal structure of human TGFBIp truncated after A657 was recently published (García-Castellanos et al., 2017). The overall structure is an elongated banana shape spanning approximately $120 \AA$ with the FAS1 domains arranged like pearls on a string (Fig. 1B). The $\mathrm{N}$ - and C-terminal residues are not observed in the structure due to the flexibility of these regions. The CROPT domain consists of a central three-stranded $\beta$-sheet and presents a novel fold (García-Castellanos et al., 2017). C65 is located on the surface in a flexible loop. The FAS1 domains are a mix of $\alpha$-helices and $\beta$-sheets, and the general architecture is $\alpha 1-\alpha 3+\beta 1+\alpha 4-\alpha 6+\beta 2-\beta 8$. The structure can be divided into a left moiety encompassing the CROPT, FAS1-1, and FAS1-2 domains and a right moiety composed of the FAS1-3 and FAS1-4 domains. The left moiety is held together by interdomain disulfide bridges and is very compact compared to the right moiety. Superposition of the left moieties of the two molecules in the asymmetric unit revealed a distance between the rightmost tips of approximately $14 \AA$ (García-Castellanos et al., 2017). This suggests that the linker between the FAS1-2 and FAS1-3 domain can work as a flexible hinge. Several studies have used single domains of TGFBIp to map functionalities and binding sites (Kim et al., 2009b; Kim et al., 2000b). We suggest that the pairwise arrangement of the FAS1 domains and the interdomain disulfide bonds are functional features. This must be taken into consideration as the domains might have altered behavior when removed from their structural context.

\subsubsection{Quaternary structure of TGFBIp}

Multimerization of TGFBIp into dimers, trimers, and tetramers has been observed in several studies (Basaiawmoit et al., 2011; Kim et al., 2002b; Ohno et al., 2002). One study suggested that disulfide bonds covalently linked the TGFBIp multimer, but this could be caused by disulfide exchange in denatured TGFBIp (Andersen et al., 2004; Ohno et al., 2002). A study of the TGFBIp structure by small-angle X-ray scattering found that TGFBIp is a monomer at low concentrations but is prone to forming dimers and trimers at higher concentrations (11 $\mu \mathrm{M})$ (Basaiawmoit et al., 2011). TGFBIp purified from human and porcine corneas was shown to be monomeric (Andersen et al., 2004). Nevertheless, considering the high concentration of TGFBIp in the cornea, it cannot be ruled out that dimers and/or trimers of TGFBIp are physiologically relevant.

\subsubsection{What can be learned from the structure of periostin?}

Periostin is a paralog of TGFBIp with $48 \%$ sequence identity and the same domain organization. The main difference between the two proteins is in the C-terminal region, which lacks the RGD motif and undergoes alternative splicing in periostin (Horiuchi et al., 1999). The structure of periostin was recently published, and the protein is similar to TGFBIp folded into a banana shape with the FAS1 domains arranged like beads on a string (Liu et al., 2018). The CROPT domain is connected to the FAS1-2 domain through a disulfide bridge, with the free C60 of periostin exposed on the surface. The free cysteine residue (C65) was found to be cysteinylated in both recombinant 
TGFBIp and endogenous TGFBIp from the cornea (Lukassen et al., 2016). However, the electron density map of TGFBIp did not indicate a modification, while the corresponding residue (C60) in the periostin structure was cysteinylated (García-Castellanos et al., 2017; Liu et al., 2018). Furthermore, the FAS1-3 and FAS1-4 domains were rotated $15^{\circ}$ between the TGFBIp and periostin structure (Liu et al., 2018). However, the two TGFBIp structures in the asymmetric unit revealed high flexibility in the hinge region between FAS1-2 and FAS1-3, which could explain that rotation. The slight differences in the structures of the two proteins indicate that even though they have a high sequence identity, the physiological functions are different.

Periostin forms a boat-like dimer in solution with a major interaction site between the CROPT domain of one molecule and the FAS1-4 domain of the other molecule (Liu et al., 2018). The most important amino acid for periostin dimerization (R463) is conserved in TGFBIp. The small-angle X-ray scattering structures of the TGFBIp dimer and trimer were elongated and not boat-like, as observed for periostin (Basaiawmoit et al., 2011). It is not known if the dimerization of periostin is concentration-dependent, as observed for TGFBIp. A study found that TGFBIp and periostin interact with each other through the CROPT domain (Kim et al., 2009a), suggesting that the interactions between the two proteins are different from those observed for the periostin dimer. Further investigation of the multimeric propensities of TGFBIp and periostin might provide more insight into the function, similarities, and differences of these two molecules.

\subsection{Protein interactions of TGFBIp}

\subsubsection{Integrins}

TGFBIp is known to bind to cell surfaces through several types of integrins present on fibroblasts, keratinocytes, endothelial cells, and epithelial cells (Table 1). The binding motif for integrin $\alpha 3 \beta 1$ has been mapped to highly conserved isoleucine and aspartate residues in the FAS1-2 and FAS1-4 domains (Kim et al., 2000b). The sequences NKDIL (residues 354-358) of the FAS1-2 domain and EPDIM (residues 614-619) of the FAS1-4 domain were identified as binding motifs (Bae et al., 2002; Kim et al., 2000b). These sequences are based on the three-dimensional structure located on the surface in a groove between the first two FAS1 domains and between the last two FAS1 domains. They are both part of a $\beta$-sheet structure and not a $\beta$-turn, as previously suggested (Park et al., 2004).

Two of the most studied integrins in relation to TGFBlp binding are $\alpha \mathrm{V} \beta 3$ and $\alpha \mathrm{V} \beta 5$ of which only $\alpha \mathrm{V} \beta 5$ is found in the cornea (Table 1) (Rayner et al., 1998). The binding motifs for these integrins have been identified as YH motifs, which correspond to residues 548-614 and contain conserved tyrosine, histidine, and flanking leucine/isoleucine residues (Kim et al., 2002a; Lee et al., 2006; Nam et al., 2006; Nam et al., 2003; Son et al., 2013; Thapa et al., 2005). The interaction between TGFBIp and integrin $\alpha \mathrm{V} \beta 3$ is, in several cases, also dependent on the RGD motif (Choi et al., 2015; Nam et al., 2006; Nam et al., 2003; Son et al., 2013). The RGD motif is a well-known integrin-binding motif, 
but as observed for integrins $\alpha 1 \beta 1$ and $\alpha M \beta 2$, it is not always required for TGFBIp interaction because the repeated FAS1 domains also have binding affinity (Kim and Kim, 2008; Ohno et al., 1999).

\subsubsection{Extracellular matrix proteins}

As mentioned in section 1.2.4, TGFBlp is reported to interact with its paralog periostin through its CROPT domains (Kim et al., 2009a). TGFBIp also binds other extracellular matrix (ECM) components, such as the glycoproteins fibronectin and laminin and the small leucine-rich proteoglycans biglycan and decorin (Billings et al., 2002; Kim et al., 2002b; Reinboth et al., 2006). The interaction between TGFBIp and fibronectin occurs through the collagen/gelatin binding domain of fibronectin (Billings et al., 2002). Decorin and biglycan bind TGFBIp via their core proteins and either share or have binding sites in close proximity on TGFBIp. Furthermore, TGFBIp forms ternary complexes with collagen type VI and small leucine-rich proteoglycans (Reinboth et al., 2006).

\subsubsection{Collagens}

Collagens are a major constituent of the corneal ECM and have been identified as TGFBIp interaction partners in several cases. Collagen types I, II, and IV are reported as noncovalent interaction partners (Billings et al., 2002; Hashimoto et al., 1997; Kim et al., 2002b), whereas collagen type VI has been found to form both noncovalent and covalent interactions with TGFBIp (Hanssen et al., 2003; Kim et al., 2002b; Rawe et al., 1997; Reinboth et al., 2006). TGFBIp and collagen type VI were copurified from rabbit corneas but required reduction to enter the SDS-PAGE gel (Rawe et al., 1997), suggesting that TGFBIp was linked to itself or other proteins, possibly collagen type VI, by disulfide bonds. The interaction between the two proteins was further characterized and showed that in vitro binding of TGFBIp to collagen type VI microfibrils occurred in a noncovalent manner (Hanssen et al., 2003). However, collagen type VI microfibrils purified from nuchal ligament tissue were covalently bound to TGFBIp through a reducible bond. The binding site was suggested to be in the $\mathrm{N}$-terminal region of the microfibrils (Hanssen et al., 2003; Reinboth et al., 2006). We found that more than half of the TGFBIp in the human cornea was bound to the insoluble ECM fraction by a reducible bond (Andersen et al., 2004). The covalent interaction partner in the cornea was shown to be collagen type XII, and the binding site is most likely in the NC3 domain (Runager et al., 2013). As mentioned in section 1.2.1, TGFBIp only has one free cysteine residue that is not involved in intramolecular disulfide bridges (Lukassen et al., 2016). We suggest that C65 in the CROPT domain is responsible for the reducible bond to collagen types VI and XII. It is not known how the amount of bound TGFBIp is regulated or when and how it is coupled to the collagens. 


\subsection{Physiological function of TGFBIp}

Several studies have suggested potential roles of TGFBIp. The ability of TGFBIp to bind both integrins and ECM molecules indicates a role in cell adhesion, and some consider it a matricellular protein (Billings et al., 2002; Kim et al., 2000a; Mosher et al., 2015; Ohno et al., 1999; Runager et al., 2013). The definition of matricellular proteins is vague, but generally, (i) they do not contribute to the structural integrity of the ECM, (ii) they are only transient constituents of the ECM, and (iii) they modulate cell function by interacting with cell-surface receptors in the ECM (Murphy-Ullrich and Sage, 2014). TGFBIp has been shown to play a role in the morphogenesis of tissues such as lung, bone, cartilage, diaphragm, heart, and cornea during vertebral embryonic development (Lindsley et al., 2005; Lu et al., 2004; Norris et al., 2005; Rawe et al., 1997; Schorderet et al., 2000). Other studies have shown involvement in processes such as angiogenesis, osteogenesis, platelet activation, wound healing, and inflammation (Kim et al., 2009b; Kim et al., 2000a; Nam et al., 2006; Nam et al., 2003; Rawe et al., 1997; Son et al., 2013; Yun et al., 2002).

Much still needs to be learned about the function of TGFBIp, and it is particularly interesting to understand in the context of the cornea due to the high abundance of TGFBIp in this tissue.

\subsection{TGFBIp in diseases}

\subsubsection{Roles in cancer}

TGFBIp plays a dual role in cancer as both a tumor suppressor and promoter (Ween et al., 2012). Several studies have reported TGFBIp as a tumor suppressor in different types of cancer, such as lung, breast, bone, ovarian, and prostate (Shao et al., 2006; Ween et al., 2011; Ween et al., 2012; Wen et al., 2011; Zamilpa et al., 2009). Strong support of the role of TGFBIp as a tumor suppressor came from the spontaneous tumor development in $\mathrm{TGFBI}^{-1-}$ mice (Zhang et al., 2009b). This is further supported by the downregulation of TGFBlp expression in many tumor types and by suppression of tumorigenicity when TGFBIp is overexpressed (Shao et al., 2006; Skonier et al., 1994; Zhao et al., 2002). A study also showed that TGFBIp expression reduced the mobility and invasive ability of tumor cells, thus reducing the metastatic potential of the cells (Ween et al., 2012; Wen et al., 2011). On the other hand, several studies have found that TGFBIp mediates cancer cell invasion and metastasis (Guo et al., 2011; Kim et al., 2003; Ma et al., 2008; Tang et al., 2007). Elevated TGFBIp expression has been linked to aggressive tumors in many cancer types (Ma et al., 2008; Sasaki et al., 2002; Zajchowski et al., 2001). These findings support the role of TGFBIp as a tumor promoter, which has been observed in cancer types such as lung (Sasaki et al., 2002), pancreatic (Schneider et al., 2002), brain (Ma et al., 2012), colon (Buckhaults et al., 2001), and ovarian (Ween et al., 2011; Ween et al., 2012).

\subsubsection{Diseases of the cornea}


TGFBIp is best known for its role in the TGFBI-linked corneal dystrophies described in detail in the following sections. However, TGFBIp is also associated with another more prevalent type of bilateral corneal disorder called Fuchs endothelial corneal dystrophy (FECD). FECD is divided into a rare early-onset and a common late-onset that affect both the innermost layer of the cornea, resulting in thickening of Descemet's membrane, the formation of corneal guttae, and abnormal cell death of the nonregenerative endothelium, ultimately leading to corneal edema. The early-onset variant has been genetically linked with mutations in collagen type VIII (Jun et al., 2012), whereas growing evidence suggests that the late-onset variant is linked to a trinucleotide repeat expansion located in the TCF4 gene (Wieben et al., 2012). Even though much effort has been put into unraveling the pathology of FECD at the molecular level, it remains unanswered. There is no genetic link between TGFBIp and FECD. However, our proteomic study on FECD tissue found significantly elevated levels of TGFBIp in patient tissue when compared to controls (Poulsen et al., 2014a). This supports previous findings by Jurkunas et al., who found TGFBlp and clusterin accumulation associated with corneal guttae formation in FECD (Jurkunas et al., 2009). Thus, even though it is most likely not the primary reason for causing FECD, the accumulation of TGFBIp in guttae may reflect downstream effects of the disease. Understanding the downstream effects of TGFBIp aggregation at the molecular level in FECD may be essential for restraining disease progression.

\section{TGFBI-linked corneal dystrophies}

\subsection{Definition and classification}

Corneal dystrophies are a group of inherited disorders that commonly affect eye transparency or shape. In 2008, the International Committee for Classification of Corneal Dystrophies (IC3D) created a new classification system to group several types of corneal dystrophies by genetic mutation (Lisch and Weiss, 2019; Weiss et al., 2015; Weiss et al., 2008). Their inheritance patterns include autosomal dominant, autosomal recessive, and X-linked modes causing amyloid and non-amyloid forms of corneal dystrophies (Korvatska et al., 2000). In many cases, a specific gene or a combination of gene mutations has been linked to specific corneal dystrophies, such as the TGFBI gene in TGFBI-linked corneal dystrophies (Chao-Shern et al., 2019).

To date, 74 mutations in TGFBI have been reported to cause various epithelial-stromal corneal dystrophies, including Reis-Bücklers corneal dystrophy (RBCD), Thiel-Behnke corneal dystrophy (TBCD), lattice corneal dystrophy type 1 (LCD1) and variants, and granular corneal dystrophy type 1 and type 2 (GCD1 and GCD2) (Table 2). This group of diseases is bilateral and inherited as an autosomal dominant trait. Studies have shown that particular TGFBI mutations cause specific corneal dystrophies. Accordingly, a genotype-phenotype correlation at two mutational hotspots, R124 and R555, has been demonstrated (Evans et al., 2016). GCD1 is one of the phenotypes that displays deposits that often have a snowflake-like appearance with well-defined granules (Copeland and Afshari, 2013) (Fig. 
2A). The genetic mutation for GCD1 is R555W. GCD2 is characterized by the progression of subtle superficial stromal whitish dots to ring/snowflake shaped gray-white granular deposits in the anterior stroma, as well as amyloid deposition (Copeland and Afshari, 2013). The mutation found is R124H. LCD1 exhibits thin branching refractile lines (Fig. 2B) and is associated with the R124C mutation (Copeland and Afshari, 2013). RBCD displays a cloud of superficial gray-white opacities, and molecular genetic studies usually reveal the R124L mutation (Copeland and Afshari, 2013). TBCD manifests as a single large honeycomb-like opacity that is associated with the R555Q mutation (Copeland and Afshari, 2013).

GCD1, LCD1, RBCD, and TBCD usually have early childhood or adolescent onsets (Table 2), while GCD2 has a different presentation. The initial age of onset is dependent on whether the patient is heterozygous or homozygous for the mutation (Copeland and Afshari, 2013). Homozygous patients are very rare and diagnosed as early as 3 years, while heterozygous patients have a delayed presentation.

\subsection{Socioeconomic burden and quality of life}

\subsubsection{Symptoms}

Blurred or cloudy vision is the most common symptom of TGFBI-linked corneal dystrophies, in addition to watery or dry eyes, light sensitivity, glare, pain, and irritation (Klintworth, 2009). In some severe cases, corneal erosion may occur where the front layer of the cornea detaches and causes mild to severe pain (Cho et al., 2012). Lesions in GCD1 carriers usually appear within the first decade with early symptoms, including glare and photophobia. Visual acuity decreases as opacity progresses with age, and recurrent white, discrete, irregularly shaped, and sharply demarcated erosions are frequently observed in these patients (Cho et al., 2012). GCD2 symptoms also appear within the first decade with painful sensation accompanying corneal erosions (Cho et al., 2012), while visual acuity usually remains good until later in life. The corneal opacities are initially small superficial white spots and subsequently become ring- or stellate-shaped stromal deposits (Weiss et al., 2008). Symptoms may present slowly in heterozygous carriers and gradually become worse. LCD1 symptoms usually develop towards the end of the first decade, while some symptoms appear during middle age. It is a slowly progressing disease that can lead to substantial discomfort and visual impairment. Corneal sensations are often lost in these patients, and the opaque filaments in the cornea resemble the network of a nervous system (Nema and Nema, 2018). The linear and other shaped opacities accumulate in the central corneal stroma, and the peripheral cornea remains relatively transparent. Symmetrical reticular opacities appear in the superficial central cornea in the first decade of life of RBCD patients. The opacities spread in a geographic-like pattern. These patients remain asymptomatic until epithelial erosions cause acute episodes of ocular hyperemia, pain, and photophobia (Klintworth, 2009). Visual acuity progressively reduces during the second and third decades of life. The superficial corneal subepithelial opacities of TBCD develop during the first and second decade of life with epithelial basal lamina and Bowman's 
layer displaying degenerative changes. TBCD is clinically similar to RBCD with a less severe course. Histological examination and molecular genetic analysis are used to differentiate the two.

Clinical aspects of TGFBI-linked corneal dystrophies are described in detail in other reviews (Klintworth, 2009; Lakshminarayanan et al., 2014; Lisch and Weiss, 2019).

\subsubsection{Epidemiology}

Klintworth reported in 2009 that TBCD was found in Germany, the USA, and other countries, while GCD was reported in India, Tunisia, Vietnam, Turkey, and the USA. Since then, more studies have been conducted on TGFBIlinked corneal dystrophies, and in 2016, Han et al. reported that GCD2 is detected more frequently in the Asian population (Han et al., 2016). The most frequently observed dystrophies in China were LCD1 and GCD2. In Western countries, LCD1 was the most commonly reported dystrophy (Han et al., 2016). However, according to Chao-Shern et al., the TGFBI mutations are distributed with no significant differences in specific population or geographical regions (Fig. 3) (Chao-Shern et al., 2019). The most reported corneal dystrophy is LCD1, followed by GCD1 and GCD2 as the second and third most reported TGFBI-linked corneal dystrophies, respectively. Late-onset LCD1/3A induced by H626R is the fourth highest reported TGFBI-linked corneal dystrophy (Chao-Shern et al., 2019).

The estimated corneal dystrophy prevalence for different populations is listed below:

- GCD2 in the South Korean population: 1 in 870 (Lee et al., 2010)

- Five most common TGFBI-linked corneal dystrophies in the Chinese population: 1 in 476 (Song et al., 2017)

- Overall corneal dystrophies in the US population according to insurance claims data: 1 in 1115 (Musch et al., 2011)

\subsubsection{Genetic testing before vision correction}

Today, laser-assisted in situ keratomileusis (LASIK) is the most popular method of vision correction and accounts for approximately $78 \%$ of refractive surgical procedures. It is a surgical procedure that provides vision correction for myopia, hyperopia, and astigmatism. A thin flap in the corneal epithelium and anterior stroma is cut and folded, and the exposed stromal layer is reshaped by laser to change its corneal focusing power. One of the most attractive aspects of the procedure is that patients have improved vision instantly after the surgery. Asia has a high myopia rate, and a study conducted by Holden et al. predicted that by 2050, the Asian-Pacific population would have the highest myopia prevalence rate among all populations at $66.4 \%$ compared to the global prevalence of $49.8 \%$ (Holden et al., 2016). With the high prevalence of myopia in these Asian populations, the use of LASIK vision correction surgery is consistently increasing and is predicted to continue to rise. In addition, given the delay in 
presentation of TGFBI heterozygote carriers, some of these patients have undergone LASIK. Many reports have unfortunately demonstrated the exacerbation of GCD2 after treatment with LASIK (Fig. 2C) (Banning et al., 2006; Chao-Shern et al., 2019; Chao-Shern et al., 2018; Chiu et al., 2007; Jun et al., 2004; Poulsen et al., 2016; Zeng et al., 2017). Therefore, genetic screening for the late onset of heterozygous mutations is recommended before laser refractive procedures, especially in patients with a family history of TGFBI-linked corneal dystrophy (Aldave et al., 2007; Chao-Shern et al., 2019; Chao-Shern et al., 2018; Copeland and Afshari, 2013).

\subsection{The $R 124$ and $R 555$ hotspots are highly mutable}

Protein interaction networks and signaling pathways are reused for different purposes at an evolutionary scale and in different cell types of the same organism (Schaefer et al., 2014). The reuse of networks with high connectivity requires high degrees of conservation at all levels: sequence, structure, and interactions. Modularity can then be achieved through additional layers of regulation, such as concerted regulation of gene expression networks. TGFBIp may control a variety of functions in different tissues and cell types and has a wide range of interaction partners, as described in sections 1.3 and 1.4. TGFBIp protein sequences are highly conserved across vertebrates (Song et al., 2014). The high degree of conservation of TGFBIp is a result of purifying selection on mutations, as most mutations in TGFBIp will have pleiotropic and detrimental effects.

As described above, a genotype-phenotype association between TGFBI mutations and cornea-specific pathologies has been established (Evans et al., 2016), revealing mutational hotspots resulting in missense changes of R124 and R555. To distinguish whether these hotspot mutations arise de novo in affected pedigrees or are passed on through shared ancestral haplotypes in the population, Korvatska et al. studied ten independently ascertained families with mutations in these hotspots (Korvatska et al., 1998). This study demonstrated that mutations occurred independently in each family in several ethnic groups and could not be explained by putative founder effects or ancestral haplotypes. Apart from the hotspot mutations and a few other pathogenic mutations in other locations, variants are evenly distributed across TGFBI exons, with 374 nonsynonymous and 166 synonymous mutations reported in dbSNP (v150). The population allele frequencies of some of the nonsynonymous mutations have been estimated, and they are all below $0.25 \%$.

The observed mutational hotspots at R124 and R555 are likely a product of survivorship bias: few other nonsynonymous TGFBI mutations are mild enough to "survive" germ cell differentiation, maturation, fertilization, and embryogenesis, processes in which TGFBIp is likely involved. In addition to survivorship bias, the overrepresentation of these two positions may be a reflection of the mutability of the underlying cytosine-guanine 
CpG dinucleotides of arginine codons. CpG dinucleotides are well-known hotspots for mutations in vertebrate genomes. This hypermutability is related to cytosine methylation followed by spontaneous deamination of 5methylcytosine to yield thymine, which, if it occurs in germlines, introduces heterozygous mutant alleles in offspring. To estimate the frequency by which this mechanism induces human disease, 54,625 missense and nonsense mutations from 2,113 genes causing inherited disease were retrieved from the Human Gene Mutation Database (HGMD) (Cooper et al., 2010). The authors found that $18 \%$ of these pathological mutations were $C \rightarrow T$ and $\mathrm{G} \rightarrow \mathrm{A}$ transitions located in $\mathrm{CpG}$ dinucleotides, compatible with the methylation-deamination model of mutagenesis. This is ten-fold higher than expected by chance alone.

\section{Biochemical mechanisms of TGFBI-linked corneal dystrophies}

\subsection{Proteomic profiling of deposits}

Aggregation of proteins into insoluble structures is a well-known hallmark of many diseases. Generally, two different aggregation pathways lead to either amorphous aggregates or highly ordered amyloid structures. Larger proteins destined for aggregation tend to follow the amorphous pathway, in which the whole protein is involved in aggregate formation. The amyloidogenic pathway often involves smaller proteins or short peptides generated by aberrant proteolytic processing of parent proteins. Studies of in vivo protein aggregates from patients with TGFBIlinked corneal dystrophy (Table 3) have shown that the dual protein aggregation propensity of TGFBIp, leading to several phenotypic outcomes, follows these general rules. While GCD, characterized by amorphous aggregates, consists of largely intact TGFBIp deposits, TGFBIp appears highly processed in the amyloidogenic phenotype LCD. Given the rarity of TGFBI-linked corneal dystrophies, there is limited access to specimen samples. Of the 74 diseasecausing mutations reported for TGFBIp, seven cases were subjected to proteomic profiling of isolated protein aggregates (Table 3). Nevertheless, these analyses have shown a clear tendency to differentiate GCD and LCD at the molecular level.

\subsubsection{Protein profiles of $G C D$ deposits}

The first article characterizing protein deposits of TGFBI-linked corneal dystrophy tissue was published in 2012 (Karring et al., 2012). The deposits were isolated from corneal formalin-fixed paraffin-embedded tissue sections using laser capture microdissection, and the protein composition was determined with tandem mass spectrometry analysis. The protein composition of the aggregates was compared with healthy control tissue to identify the accumulating proteins. This approach has been applied in subsequent studies by ourselves and others that determined the protein aggregate compositions related to TGFBI-linked corneal dystrophies (Courtney et al., 2015; Karring et al., 2013; Poulsen et al., 2016; Poulsen et al., 2014b; Venkatraman et al., 2017). 
To date, two studies have been published characterizing the protein profiles of GCD1 (R555W mutation) and GCD2 cases (R124H mutation). The first study (Karring et al., 2012) showed amorphous aggregates of intact or nearintact TGFBIp accumulated in GCD2. This finding correlates well with work by Klintworth et al., 1998, who looked at whole corneal GCD2 tissue not subjected to microdissection (Klintworth et al., 1998). Later, Courtney et al., 2015 showed the same tendency of intact TGFBIp aggregation in GCD1 caused by the R555W mutation in the FAS1-4 domain (Courtney et al., 2015). Thus, despite the considerable distance in the primary sequence, GCD caused by a mutation either in the FAS1-1 or FAS1-4 domain resulted in corneal aggregates of intact TGFBIp and with similar phenotypic outcomes. In addition to elevated TGFBIp levels in GCD deposits, the protein profile of the cases resembles healthy corneal stroma to a high degree. Courtney et al., 2015 only found three unique proteins associated with GCD1 deposits not present in control tissue, including hemoglobin subunit beta, actin cytoplasmic 1, and desmoplakin. In the study of GCD2 deposits, serum amyloid P (SAP), type III collagen, clusterin, and histone H3-like protein were enriched in GCD2 aggregates (Karring et al., 2012).

Interestingly, in addition to multiple other binding partners (Poulsen et al., 2017), SAP usually associates with amyloid deposits of various misfolding diseases (Pepys et al., 1979). However, SAP was not identified either in the GCD1 deposits or in the control tissue, which was also the case for GCD2 deposits, where protein aggregation had been unintentionally triggered by LASIK surgery (Poulsen et al., 2016). As SAP is a generic biomarker for amyloid depositions, the presence of SAP in naturally progressed GCD2 aggregates may be indicative of an amyloid undergrowth masked by the amorphous aggregates. Eventually, amyloid appearances are observed in the later stage of some GCD2 patients, thereby giving rise to its characteristic mixed phenotype. This observation also suggests that naturally progressing amorphous aggregates in GCD2 follow a different molecular pathway than LASIK-induced GCD2 aggregates.

\subsubsection{Protein profiles of $L C D$ deposits}

The protein profiles of the LCD deposits are different from the GCD cases and control tissue. The only common denominators linking LCD and GCD deposits appear to be the accumulation of TGFBIp as well as the chaperone protein clusterin. The protein profiles of amyloid LCD deposits from patients carrying R124C, A546D, A546D/P551Q, V624M, or H626R TGFBIp mutations show the accumulation of other amyloidogenic proteins in addition to TGFBIp, as well as nonfibrillar amyloid-associated proteins. The amyloidogenic proteins include apolipoprotein A-I, apolipoprotein A-IV, lysozyme C, protein S100-A8, protein S100-A9, and lactotransferrin (Courtney et al., 2015; Karring et al., 2013; Karring et al., 2012; Poulsen et al., 2014b; Venkatraman et al., 2017). Whether the amyloidogenic proteins are directly involved in the progression of amyloid deposits or merely innocent coaggregating bystanders is not known. The nonfibrillar amyloid-associated proteins involve SAP, clusterin, apolipoprotein E, apolipoprotein D, prostaglandin-H2 D-isomerase, complement component C9, decorin, and 
cystatin-A. Finally, the protein profiles of amyloid deposits identified several proteins involved in proteolysis. The serine protease high-temperature requirement A1 (HtrA1) was associated with all LCD cases, whereas kallikrein-14 was only identified in the A546D deposits (Karring et al., 2012). Carboxypeptidase B2 (also known as TAFI), caspase14, cathepsin D, cathepsin L2, and plasminogen were identified solely in deposits of A546D/P551Q patients (Poulsen et al., 2014b). Moreover, the protease inhibitor cystatin-A was identified in amyloid deposits of A546D, A546D/P551Q, and R124C cases. Glia-derived nexin, a serpin inhibitor, was only identified in A546D deposits, while metalloprotease inhibitors 1 and 3 and serpin B12 were only identified in A546D/P551Q amyloid deposits. Although all proteases and inhibitors are constituents of the healthy corneal proteome (Semba et al., 2013), their association with the amyloid deposits suggests extensive proteolytic activity in LCD. In contrast, no proteins involved in proteolysis were detected in GCD deposits.

Analysis of TGFBIp in amyloid deposits with a mutation in the FAS1-4 domain showed extended accumulation of various ragged isoforms of two polypeptide regions in FAS1-4 (Karring et al., 2013; Karring et al., 2012; Poulsen et al., 2014b; Venkatraman et al., 2017). For simplicity, these two polypeptide regions have been designated as the F515-R533 and Y571-R588 peptides in the literature, referring to the first (e.g., 515) and last (e.g., 533) amino acid number in the protein sequence of TGFBIp. The two peptides are obtained after the enzymatic cleavage of TGFBIp by trypsin (also referred to as tryptic peptides) generally used in sample preparation for mass spectrometry analyses. Both peptides are prone to in vitro amyloid fibrillation. Interestingly, amyloid fibrils composed of synthetic F515-R533 and/or Y571-R588 peptides were able to seed amyloid fibrillation of the FAS1-4 domain carrying the LCD-linked A546T mutation. Furthermore, non-amyloid coprecipitation of TGFBIp isolated from corneal extract was achieved using these synthetic fibrils (Sørensen et al., 2015), suggesting that once formed, amyloid aggregates may accelerate the formation of deposits by initiating additional aggregation events in the cornea.

Endogenous cleavage sites observed for TGFBIp in amyloid deposits show enzymatic preferences for cleavage after the aromatic and hydrophobic amino acid residues $(A, F, H, I, L, M, V, W$, and $Y)$, as well as the hydrophilic amino acids T, N, Q, D, and E (Courtney et al., 2015; Karring et al., 2013; Karring et al., 2012; Poulsen et al., 2014b; Venkatraman et al., 2017). Interestingly, the specificity of the serine protease HtrA1 is directed towards hydrophobic amino acid residues (Truebestein et al., 2011), supporting the involvement of HtrA1 in the in vivo processing of TGFBIp as these cleavage sites are highly represented in in vivo amyloid deposits.

\subsection{Proteolytic processing}

\subsubsection{Tissue-specific processing of TGFBIp}

The use of in vitro TGFBIp observations to understand the physiological behavior of TGFBIp in the cornea is complicated by several aspects. Authentic corneal TGFBIp appears to be heterogeneously modified or interact with other corneal components, as demonstrated by immunoblotting of corneal tissue separated by two-dimensional 
gel electrophoresis (Fig. 4), resulting in aberrant behavior during two-dimensional gel electrophoresis producing a TGFBIp band across the gel. In addition to the full-length TGFBIp band, a characteristic zigzag pattern is observed for corneal TGFBIp. This zigzag pattern is a result of posttranslational N-terminal trimming of TGFBIp, of which the smallest degradation products span the FAS1-4 region of TGFBIp (Karring et al., 2010). Therefore, the full-length protein and the FAS1-4 domain appear to be good model systems for studying TGFBI-linked corneal dystrophies, as they are the major start and end products in the cornea. The complexity is further increased by the appearance of two TGFBIp fractions in humans, an insoluble fraction and a soluble fraction. The insoluble fraction constitutes approximately 60\% (Andersen et al., 2004) and is covalently bound to the corneal ECM (Runager et al., 2013) via a reducible bond to C65 of TGFBIp (Lukassen et al., 2016). As protein aggregation in TGFBI-linked corneal dystrophies is most likely concentration-dependent, it would be interesting to investigate whether the bound to free ratio of TGFBIp differs in TGFBI-linked corneal dystrophy patients compared to healthy individuals. A shift in the ratio towards an increase in soluble TGFBIp protein is expected to fuel aggregation.

Intriguingly, the deposition of TGFBIp appears to be specific to the cornea even though TGFBIp is widely expressed in many tissues (Runager et al., 2008). This finding argues for a unique extracellular environment in the cornea necessary for nurturing the disease progression of TGFBI-linked corneal dystrophies. Support for this theory is shown by comparing the in vivo degradation pattern of TGFBIp originating from healthy cornea, skin, plasma, and platelets (unpublished observation) (Fig. 4). Though extensively processed, skin TGFBIp is confined to a smaller isoelectric point range and differs in its degradation pattern. Plasma and platelet TGFBIp show only a few degradation products compared to the cornea.

\subsubsection{HtrA1 proteolysis in $L C D$}

The human serine protease HtrA1 is a homotrimeric nonglycosylated serine protease. The $51 \mathrm{kDa}$ monomeric subunit is composed of four domains: the N-terminally IGFBP-like and Kazal-like domains, a central catalytic domain, and lastly, a C-terminal PDZ domain. While the PDZ domain has been associated with substrate recognition (Runyon et al., 2007) and facilitates binding to amyloid fibrils (Poepsel et al., 2015), the role of the two N-terminal domains remains unknown. We have shown that HtrA1 undergoes in vitro redox-mediated autolysis by the protein thioredoxin (Risør et al., 2014), which we found associated with two LCD cases (Karring et al., 2013; Poulsen et al., 2014b). However, HtrA1 autolysis does not appear to affect its specificity or its activity (Poulsen et al., 2019) and therefore remains an enigma. The promiscuous specificity of HtrA1 for hydrophobic sequences might support a role for HtrA1 in protein quality control, as observed for its bacterial homologs (Runyon et al., 2007). In addition to LCD, HtrA1 has been associated with several pathological disorders. These include various types of cancer (ZurawaJanicka et al., 2010), age-related macular degeneration (Vierkotten et al., 2011), Alzheimer's disease (Grau et al., 2005), and immunoglobulin light chain amyloidosis (Nielsen et al., 2014). The presence of HtrA1 across all cases of 
LCD amyloid deposits suggests a role either in disease progression or in removing protein aggregates. HtrA1 has been found throughout the healthy corneal stroma (Poulsen et al., 2019) and is a relatively abundant protein in Descemet's membrane and the endothelial layer of the cornea (Dyrlund et al., 2012). Furthermore, peri-amyloid tissue (stromal tissue from LCD patients without apparent protein deposits) was enriched in HtrA1 compared to control tissue in the studies of A546D and H626R deposits (Karring et al., 2013; Venkatraman et al., 2017). This implies that HtrA1 is involved in corneal proteostasis and that its presence in LCD most likely reflects an attempt to remove misfolded TGFBIp protein in the prefibrillar stage. HtrA1 has been ascribed a role in disintegrating the amyloid structure in vitro (Poepsel et al., 2015). The disintegrating capacity of HtrA1 in LCD seems to be minor as the severity of the disease increases with age.

To validate TGFBIp or some of its degradation products as HtrA1 substrates, the in vitro proteolysis of wild-type and mutant TGFBIp and FAS1-4 proteins was analyzed (Poulsen et al., 2019). HtrA1 showed the highest preferences for mutant TGFBIp associated with the LCD phenotype, especially when using the FAS1-4 domain as a substrate (consistent with the increased protease sensitivity of these mutants (Stenvang et al., 2018)). Furthermore, degraded FAS1-4 formed amyloid fibrils consisting mainly of peptides overlapping with the Y571-R588 region highly represented in in vivo LCD deposits. Examining the degradation pattern of LCD tissue from A546D and V624M clearly showed a reduction in TGFBlp degradation products (Poulsen et al., 2019), but this is not the case in GCD2 (unpublished data). This suggests that HtrA1 removes TGFBIp degradation products in LCD tissue and, because of this process, liberates peptides prone to amyloid fibrillation, which - together with the inherent tendency of the unfolded state of TGFBIp to aggregate (see below) - may be a driving force in disease progression.

\subsection{The FAS1-4 domain mimics many properties of full-length TGFBIp, making it an excellent model system}

Corneal dystrophy-causing mutations are most frequently observed in the C-terminal FAS1-4 domain (Table 2). This distribution of the disease-promoting amino acid substitutions indicates that the FAS1-4 domain is important for the stability of the intact protein. Indeed, three FAS1-4 amino acid substitutions, including A546T associated with LCD (generates an unstable FAS1-4 domain) and R555W causing GCD1, or R555Q leading to TBCD, (both generate FAS1-4 domains comparable to wild type), affected the stability of the isolated FAS1-4 domain and the full-length protein in a similar way (Runager et al., 2011). For FAS1-4, the same stability ranking was obtained using both urea and thermal denaturation, emphasizing the robustness of the conclusions. In addition, deamidation rates as a measure of structural integrity were similar for corresponding FAS1-4 and TGFBIp mutants (Nielsen et al., 2017). In line with these results, FAS1-4 was more sensitive to trypsin cleavage than the other three FAS1 domains, indicating that it is the most conformationally unstable domain in TGFBIp (Runager et al., 2011). The correlation between FAS1-4 and full-length TGFBIp was further supported by the similar behavior of the FAS1-4 domain in vitro and the TGFBIp aggregates observed in vivo. The unstable FAS1-4 LCD mutant A546T formed amyloid deposits in 
vitro within a few days, whereas the more stable R555W and R555Q (which led to amorphous aggregates in vivo) did not form visible aggregates even after 1 week of incubation, which implies that the aggregation in GCD and TBCD follows another aggregation pathway that is either slower than the amyloid-forming pathway or requires biological factors absent in our in vitro experiments (Runager et al., 2011). The structure of TGFBIp provides some clues about the critical importance of the C-terminal FAS1-4 domain for the overall stability of TGFBIp (GarcíaCastellanos et al., 2017). Several interdomain contacts between CROPT and the first two FAS1 domains are apparent; furthermore, the two interdomain disulfide bonds, as well as two of the three intradomain disulfide bonds in TGFBIp, are found within these three domains (Lukassen et al., 2016) (the remaining intradomain disulfide bond is in FAS1-3). In contrast to these intermolecular interactions, only a small interface between FAS1-4 and FAS1-3 is evident, making FAS1-4 a "hanger-on" domain where the destabilizing effects of mutations in the core of the protein cannot be offset by stabilizing interdomain contacts. The properties of the FAS1-4 domain make it a convenient model for studies aimed at understanding the propensity of TGFBIp to aggregate or for amyloid fibrils.

\subsection{A comprehensive mutagenic and bioinformatics study highlights fundamental differences between LCD and GCD} mutants

Building on the connection between FAS1-4 stability and phenotype (Runager et al., 2011), we systematically probed the link between the clinical manifestations of TGFBI-linked corneal dystrophy mutations and their underlying molecular impact on protein folding and stability. Our study encompassed 30 FAS1-4 mutants, spanning both LCD as well as GCD1, variant GCD2, and TBCD (Stenvang et al., 2018). Recombinantly expressed mutants (which included a tryptophan residue introduced to aid spectroscopic measurements) were analyzed in terms of their tendency to oligomerize in solution, stability against urea and thermal denaturation, tendency to expose hydrophobic surface area, sensitivity to protease digestion, protein folding/unfolding dynamics, and tendency to form amyloid in the presence of the glycosaminoglycan (GAG) heparin. The outcome confirmed and extended our previous conclusions. Thus, all LCD mutations were destabilizing; in fact, 14 of the 15 FAS1-4 mutants that we failed to purify all belonged to this class, illustrating their debilitating effects on FAS1-4 stability. Of the 15 that were expressed sufficiently well enough to be purified, eight spontaneously formed soluble oligomers and, in some cases, underwent a noncooperative unfolding when exposed to chemical denaturants. In addition to wild type, this only left six mutants sufficiently "well-behaved" to form a folded monomeric state. Of these, both LCD mutants and the variant GCD2 mutant were destabilizing; these mutants also exposed more hydrophobic surface area (i.e., were "sticky") and readily succumbed to trypsin degradation. Remarkably, despite a similar lack of stability, the LCD mutants formed amyloid significantly better than their GCD2 counterpart, and the aggregates formed by the variant GCD2 mutant (like the GCD1 mutant R555W) were non-amyloid (Stenvang et al., 2018). 
Based on this overall confirmation of the destabilizing properties of LCD mutants, we carried out a comprehensive computational analysis of the known and predicted properties of all known FAS1-4 mutations associated with TGFBI-linked corneal dystrophies and reached some striking conclusions (Stenvang et al., 2018). When grouped on the FAS1-4 structure, all 29 LCD mutations and both variant GCD2 mutations occur in buried positions, while GCD1 and TBCD mutations are found at relatively exposed sites. Furthermore, all but one of the known LCD mutants are predicted to be destabilizing; conversely, most positions in the FAS1-4 sequence that are sensitive to mutation (i.e., which are expected to be destabilized if mutated from the wild-type residue) are associated with an LCD mutation. Nevertheless, the LCD mutations are not predicted to increase the aggregation propensity of FAS1-4 (Stenvang et al., 2018). This highlights a very important point: LCD mutations induce aggregation because they increase the population of unfolded FAS1-4, not because the unfolded state becomes more aggregation-prone due to the mutation. The more buried the mutation site is, the more destabilizing the mutation and the more difficult it was to purify the mutant, and the higher the tendency of the mutant to oligomerize and aggregate even if it could be expressed. This means that studies that attempt to recapitulate TGFBIlinked corneal dystrophies by studying the impact of mutations on small (and largely unfolded) peptide fragments of FAS1-4, though well-intentioned, are misleading because they fail to capture the true effect of the mutation, which is to increase the proportion of unfolded protein. Correspondingly, they fail to link the clinical phenotypes with peptide aggregation properties (Lakshminarayanan et al., 2011; Yuan et al., 2007). This is borne out by the properties of the peptide corresponding to the sequence Y571-R588 that has been identified as the core of TGFBIp fibril deposits (Sørensen et al., 2015). There are very few TGFBI-linked corneal dystrophy-causing mutations in this part of the TGFBIp sequence; in contrast, many different types of LCD mutations lead to the same fibril deposit. Most likely, the aggregation propensity of this peptide sequence (which is already highly amyloidogenic) cannot be improved by mutagenesis, and the main impact of mutations is to increase the propensity to expose the peptide to solvent so it can aggregate through interactions with other copies of the same protein.

It seems counterintuitive that aggregation of TGFBIp is promoted by the near-wild-type stability of R555Q (TBCD), let alone by a stabilizing mutation such as R555W (GCD1), which also increases its resistance to proteolytic degradation (Underhaug et al., 2013). However, our bioinformatics analysis also shed intriguing light on the effects of these mutations, namely, reduced solubility of the folded monomeric state (Stenvang et al., 2018). The charged side-chain R555 is highly exposed, and replacement with a large aromatic side-chain tryptophan (or less dramatically with a polar residue glutamine) is predicted to increase the protein's tendency to precipitate according to the CamSol method (Stenvang et al., 2018). In contrast, variant GCD2 mutations decrease stability rather than solubility, but the nature of the mutation (M619K and L550P) may be incompatible with amyloid formation and lead to a faster non-amyloid aggregation pathway. Thus, GCD mutations can influence the nature of the ensuing aggregate much more decisively than LCD mutants that simply increase the tendency to unfold. 
Interdomain mutations, i.e., mutations at the interface between domains, will have effects that go beyond the individual domain and should therefore properly be studied using multiple domain constructs. However, the fact that we can account for the great majority of predicted and measured LCD and GCD mutant properties from physical-chemical considerations based on the structure of the isolated FAS1-4 domain strongly suggests that the great majority of TGFBI-linked corneal dystrophy mutations are linked to intradomain effects.

\subsection{Impact of glycosaminoglycans on fibrillation mechanisms}

The key event in TGFBI-linked corneal dystrophies is the aggregation of intact or fragmented TGFBIp to insoluble deposits, which cloud the cornea and impair vision. Consequently, the mechanisms of aggregation are of great interest, not least in the context of the corneal environment. Aggregation of FAS1-4 variants such as the LCD mutant A546T is multifactorial and influenced by multiple features, including the concentration of protein and salt, which can affect both the rapidity of the aggregation process, the species that accumulate along the way and the nature of the final aggregate (Andreasen et al., 2012).

A central feature is the involvement of sulfated GAGs such as heparin. This highly anionic biomacromolecule is known to stimulate the aggregation of many different proteins and peptides in vitro and in vivo (Malmos and Otzen, 2014). It may do so by templating proteins into a conformation conducive for amyloid formation (Christensen et al., 2016; Malmos et al., 2017a) or by increasing the local concentration of the protein (Nielsen et al., 2012) while at the same time neutralizing positive charges that could otherwise impede the initiation of fibrillation. In the case of FAS1-4, aggregation of wild type and the GCD mutants (which in any case occurs with very low efficiency) is not affected by heparin. In contrast, heparin significantly promotes aggregation of destabilized LCD mutants (Andreasen et al., 2012; Stenvang et al., 2018), reducing or even eliminating the lag time before the onset of fibrillation as well as increasing the overall yield of amyloid. Amyloid formation is preceded by the formation of heparin-stabilized oligomers (Malmos et al., 2017b); for both amyloid and oligomers, heparin appears to work catalytically since no stable complexes between protein and heparin can be detected. GAGs vary in the extent of their sulfation, with heparin being the most highly sulfated and hyaluronic acid not sulfated at all. Both oligomer yields and the rapidity of fibrillation increase with the extent of sulfation and glycan length (Malmos et al., 2017b). This observation is all the more remarkable, given that the proportion of highly sulfated GAGs increases dramatically with age in the cornea (Pacella et al., 2015), possibly to maintain a high level of hydration in the stromal layer of the cornea (Massoudi et al., 2016). LCD mutations in many cases lead to corneal dystrophy symptoms after 20-30 years (Table 2), which corresponds to the period in which GAG sulfation starts to increase. This suggests that increased GAG sulfation may drive LCD. 


\subsection{Proposed mechanisms of action in TGFBI-linked corneal dystrophies}

It is evident from the in vitro and in vivo results presented in the previous sections that several biochemical mechanisms are involved during TGFBlp aggregation in TGFBI-linked corneal dystrophies. A summary of the proposed mechanisms involving disease-causing mutations in the FAS1-4 domain is shown in Fig. 5. Even though they are less understood at the molecular level, attempts to describe the aggregation mechanisms for mutations in the FAS1-1 domain will be touched upon briefly. Disease-causing mutations in the FAS1-1 domain associated with GCD2 (R124H) and RBCD (R124L) preserve the thermodynamic stability of full-length TGFBIp compared to wild type (Runager et al., 2011). In addition, X-ray crystallography did not reveal structural perturbation of TGFBIp upon the introduction of the $\mathrm{R} 124 \mathrm{H}$ mutation (unpublished observation). This makes sense, as R124 is surface exposed in the structure of wild-type TGFBIp and, therefore, as proposed for GCD- and TBCD-linked mutations in the FAS1-4 domain, might lead to a decrease in solubility of TGFBIp. Even though the structural fold of TGFBIp was not compromised, these FAS1-1 mutations may still disturb the normal turnover and/or affect the interplay between TGFBIp and the extracellular milieu (Fig. 5B).

In contrast to LCD-associated mutations in the FAS1-4 domain, the LCD1-linked mutation R124C in the FAS1-1 domain does not affect the stability of full-length TGFBIp (Runager et al., 2011). In addition, the accumulation of the Y571-R588 region appears less important for amyloid formation (Courtney et al., 2015). Instead, data have shown that a 22 amino acid region spanning residue R124 in FAS1-1 is capable of forming amyloid material in vitro upon the introduction of the R124C mutation, whereas native peptide showed minor potential to form amyloid fibrils (Schmitt-Bernard et al., 2000a). Thus, introducing the R124C mutation may turn the FAS1-1 domain amyloidogenic, which is supported by the finding of N-terminal accumulations of TGFBIp in R124C corneas (Korvatska et al., 2000). In contrast, the amyloidogenic nature of FAS1-4 is suppressed in wild-type TGFBIp and is released only upon mutation-induced structural destabilization.

We cannot rule out the possibility that other mechanisms might contribute to the accumulation of TGFBIp. In the case of GCD2, extensive studies of the molecular pathogenesis have been carried out focusing on pathological differences between normal and GCD2 corneal fibroblasts, which have been well described by Han and colleagues (Han et al., 2016).

\section{Treatment strategies}

\subsection{Current treatment options}


Patients with TGFBI-linked corneal dystrophy typically present with two types of symptoms: 1) Foreign body sensation or even pain due to deposits protruding into and through the corneal epithelium, and 2) blurred vision and light sensitivity due to deposits in the epithelium and corneal stroma, which causes light scatter.

Therefore, treatments aim to smooth the corneal stromal surface and remove deposits from the corneal stroma in the form of keratectomy or corneal transplantation. The depth of the opacities has traditionally been evaluated by slit-lamp biomicroscopy, but today anterior segment optical coherence tomography is commonly used as more detailed information is provided (Hong et al., 2011; Siebelmann et al., 2018).

\subsubsection{Keratectomy}

Before the implementation of excimer lasers in corneal surgery, simple scraping and removal of the corneal epithelium and sometimes the superficial stroma using a surgical crescent knife was the initial treatment.

At the beginning of the 1990s, excimer laser ablation of corneal tissue was used and is today almost exclusively used for removal of deposits in TGFBI-linked corneal dystrophies (Fagerholm, 2003; Fagerholm et al., 1993). The procedure is known as phototherapeutic keratectomy (PTK). Excimer lasers used in ophthalmology are based on ArF, which, under appropriate electrical stimulation, are excited and then give rise to 193-nm laser light. The laser pulses have sufficient energy to disrupt the molecular bonds of the corneal surface tissue, which disintegrates into the air through ablation rather than burning.

The extent of PTK treatment of TGFBI-linked corneal dystrophy depends on the localization of deposits. In the past, the epithelium was typically removed first by alcohol-assisted debridement, which required the use of a masking agent filling the space between epithelial protrusions. Today, the epithelium itself is typically used as a masking agent, and PTK is performed directly on the undisturbed surface. The epithelium and epithelial deposits are always ablated, while the extent of stromal ablation is individualized (Seitz and Lisch, 2011). In superficial TGFBIlinked corneal dystrophy such as TBCD, all deposits may be removed. In other dystrophies with a deeper location, such as GCD1 and LCD, deposits left as ablations deeper than $100 \mu \mathrm{m}$ of the corneal stroma may cause significant side effects.

After PTK treatment, epithelial healing takes place over a few days, and vision typically recovers and becomes stable during the following weeks. As excimer laser treatment profiles used for PTK typically ablates more tissue in the center of the cornea, the corneal surface becomes flatter, which results in a hyperopic shift. Performing an excimer laser treatment for hyperopia in combination with the PTK treatment may reduce this refractive side effect (Amano et al., 2016). Deep ablations are associated with the development of haze in the corneal stroma. The haze typically peaks 3 months after treatment and can cause visual side effects. Peroperative application of mitomycin- 
C on the ablated stroma seems to reduce the development of haze (Ayres et al., 2006) but is inefficient in patients with GCD2 (Ha et al., 2010) and is not recommended (Han et al., 2016).

As TGFBI-linked corneal dystrophies are epithelial in origin, recurrence of deposits will occur over the years after PTK treatment. The duration before clinically significant deposits recur depends on the specific type of dystrophy (Han et al., 2016), but there are considerable individual variations even between family members.

\subsubsection{Corneal transplantation}

Corneal transplantation has been used for more than 50 years to treat patients with significantly decreased vision due to TGFBI-linked corneal dystrophy. Corneal transplantation can be performed as penetrating keratoplasty (PK) in which the full thickness of the cornea in a 7.5- or 8.0-mm diameter is replaced with a clear corneal donor graft. The graft is fixed with Nylon sutures, which must remain for 12 to 18 months.

As the corneal endothelium is normal in patients with TGFBI-linked corneal dystrophy, anterior lamellar corneal transplantation is often preferred. The lamellar transplantations are typically performed as a deep anterior lamellar keratoplasty (DALK) although superficial anterior lamellar keratoplasty (SALK) may become an alternative when safety and efficacy issues are further studied. For the past 20 years, the DALK procedures have been further developed to preserve only Descemet's membrane with endothelium in the recipient using the so-called big-bubble technique (Anwar and Teichmann, 2002). The visual outcome of this procedure is comparable to the PK procedure but preserves the endothelium of the recipient. Visual recovery is often slow after the PK and DALK procedures and takes up to two years. Even then, many patients end up with considerable corneal astigmatism, which necessitates spectacle wear or use of rigid gas-permeable contact lenses. In addition, the grafted eye will be more vulnerable to blunt trauma with the risk of wound rupture and associated significant complications for the rest of the patient's life. As recipient corneal epithelium will exchange the donor epithelium over weeks or months, TGFBI-linked corneal dystrophy will also inevitably recur in the donor graft after PK and DALK over the years after surgery (Ellies et al., 2002; Fagerholm, 2016; Kawashima et al., 2006). However, recurrence is slower than that observed after PTK (Lewis et al., 2017).

In SALK, typically only the anterior half of the corneal stroma is excised and exchanged with human donor corneal tissue. Various surgical techniques have been used, but today, either a microkeratome (Fogla and Knyazer, 2014) or a femtosecond laser (Lee et al., 2018; Yoo et al., 2008) is used for the mid-stromal slicing of the corneal lamellae. If great care is taken concerning correct diameter sizing of the donor graft, the graft will attach passively in the recipient cornea without sutures. A bandage contact lens is typically used the first weeks until epithelialization of the graft surface has taken place. The advantage of the SALK procedure is fast visual rehabilitation and a more robust eye globe, although the final visual acuity may be inferior to DALK due to scattered rays arising from the stromal interface. As TGFBI-linked corneal dystrophy will recur in the graft over time, an additional advantage is the 
possibility of a relatively easy re-transplantation after SALK, as the original donor graft can be bluntly loosened from the recipient bed. On the other hand, severe worsening of GCD2 has been observed after LASIK performed for refractive errors (Jun et al., 2004; Poulsen et al., 2016). As the SALK procedure also involves intrastromal cutting of the anterior stroma, this procedure should not be considered a standard and safe procedure in TGFBI-linked corneal dystrophies until further safety and efficacy studies are performed.

In addition to the recurrence of the original disease after keratoplasty, grafted patients may experience the same complications as other patients undergoing corneal transplantation, which may all result in graft failure: rejection episodes and suture-related complications (suture breaks, wound leakage, keratitis, etc.). Clinically significant rejection episodes are most often directed towards the corneal endothelium, which is an important incentive to perform anterior lamellar grafts (Borderie et al., 2012) rather than penetrating grafts in patients with TGFBI-linked corneal dystrophy.

\subsubsection{Staged treatment of TGFBI-linked corneal dystrophies}

TGFBI-linked corneal dystrophies cannot be cured by surgery or any other treatments. The goal is to preserve lifelong useful vision and minimally disturbed eye comfort. The initial surgical treatment is PTK, which often can be repeated two to three times when the dystrophy recurs. PTK treatments are performed as shallowly as possible to preserve as much corneal stroma as possible for repeated treatments, although this must be balanced towards the visual benefit for the patient. If PTK cannot be repeated any longer due to thinning of the corneal stroma or in cases where the deposits are prominent deeper in the corneal stroma, anterior lamellar transplant procedures in the form of SALK or DALK can be utilized.

\subsection{Animal models}

Animal models are crucial for determining the physiological function of different proteins and for understanding the pathophysiology of various diseases. They are also an important tool in the development and testing of novel treatment strategies. When choosing an animal model, you aim for high resemblance of anatomy and molecular composition to the human tissue, in this case the human cornea. However, the animals with the highest resemblance, such as pigs, sheep, and dogs, are costly and take a long time to develop. The choice often falls on smaller animals such as rabbit, rat, mouse, and zebrafish, with mouse being the most popular, as is the case for animal models related to TGFBIp and TGFBI-linked corneal dystrophy.

\subsubsection{Current TGFBI mouse models}


Mouse models have been used to investigate the physiologic and pathologic roles of TGFBIp by either knockout or overexpression (Table 4). Due to the role of TGFBIp in TGFBI-linked corneal dystrophy, there has been a focus on the morphology and transparency of the cornea, and a few transgenic mouse models expressing mutant TGFBIp have been developed (Table 4).

\subsubsection{Knockout mouse models}

The first TGFBI-null mouse model was used to investigate the role of TGFBIp as a tumor suppressor (Zhang et al., 2009b). This study showed that TGFBI-deficient mice were predisposed to spontaneous tumor development. The body weight of the mice was decreased, which was caused by reduced bone size and bone mass (Yu et al., 2012). Histological examinations of organs such as the liver, lung, kidney, stomach, intestine, and testis did not reveal any abnormalities. Additionally, the eyes of these mice did not show any phenotype. Recently, we performed a thorough examination of the corneal structure of another TGFBI-null mouse model (Poulsen et al., 2018). In agreement with the previous study, we did not detect any effect of TGFBI deficiency on the gross corneal structure. However, this mouse model showed abnormal lung morphology and function in another study (Ahlfeld et al., 2016). Other studies have examined the consequences of knocking out TGFBI in organs other than the cornea (Table 4).

\subsubsection{Overexpression mouse models}

The effect of elevated levels of circulating TGFBIp on eye development was investigated in a mouse model with liver-specific overexpression of human TGFBIp (Kim et al., 2007). The size and organs of the transgenic mice were normal, but some mice showed corneal phenotypes. These included corneal opacity, which was caused by corneal endothelial disruption and not by the accumulation of TGFBIp. Other anterior defects included disorganized corneal collagen structure, cataract, and corneolenticular adhesion. Thus, the study concludes that TGFBIp might be involved in anterior segment morphogenesis and eye development (Kim et al., 2007). Another mouse model overexpressing human TGFBIp under the control of the phosphoglycerate kinase promoter showed similar corneal opacities when eyelids opened at approximately two weeks after birth (Liao et al., 2013). This study did not perform any histological examination of the anterior segment of the transgenic mice, and we cannot conclude if the opacities are caused by TGFBIp accumulation or disrupted corneal endothelium. The early onset and appearance of the opacities point towards anterior segment dysgenesis (Kim et al., 2007).

\subsubsection{TGFBI mutant mouse models}

Two of the most common mutations in TGFBI are R555W associated with GCD1 and R124H related to GCD2. These mutations have been the target of studies attempting to create TGFBI-linked corneal dystrophy mouse models. A transgenic mouse model overexpressing TGFBI containing the R555W mutation, unfortunately, did not 
express the transgene in the cornea. Hence, no corneal phenotype was observed (Bustamante et al., 2008). Instead, age-dependent retinal degeneration and possible accelerated aging were detected. In another study, a GCD2 mouse model was generated by inserting the human cDNA containing the $\mathrm{R} 124 \mathrm{H}$ mutation into the first intron of the mouse TGFBI gene (Yamazoe et al., 2015). Heterozygous and homozygous mice of this model developed granular deposits with or without amyloid deposits. The incidence of corneal opacity was increased in aged mice of 60-79 weeks with incidences of $67 \%$ in homozygotes and $29 \%$ in heterozygotes (Yamazoe et al., 2015). The phenotype resembled human cases but differed in severity and amount of amyloid deposits, suggesting a difference compared with human disease. During a recent study of the corneal proteome of this mouse model, we failed to detect any deposits (unpublished results). We found that the amount of mutated TGFBIp was $41 \%$ compared to the wild-type protein, which indicated a reduction in transgene expression. This could be caused by a lack of introns in the transgene, which can cause lower expression in mice (Choi et al., 1991). Another cause could be methylation of the promoter. We suggest that the lack of corneal deposits in this case was caused by the low amount of mutated TGFBIp. Furthermore, the protein profiles of the corneas were not affected by transgene expression or lowered amounts of TGFBIp (unpublished results).

\subsubsection{Future directions for TGFBI animal model generation}

The TGFBI knockout mouse models did not show any corneal phenotype, which is surprising since TGFBIp has been hypothesized to play a role in the corneal ECM. Lack of phenotype development in knockout mouse models is a common phenomenon (Barbaric et al., 2007). The lack of phenotype can be due to genetic robustness caused by alternative pathways or proteins with redundant functions. In addition, we found that the TGFBIp amount in the mouse cornea was 10-fold lower than in human corneas (Poulsen et al., 2018). Hence, the effect of TGFBI knockout in the mouse cornea might not have as severe consequences as in the human cornea. Thus, overexpression of TGFBI in mouse models will resemble the human case to a higher degree. The ontogenetic effects caused by TGFBI overexpression, such as anterior segment dysgenesis, could potentially be avoided by inducible expression and could be combined with a tissue-specific promoter, such as the corneal epithelium K12 promoter. Animal models other than mice with more TGFBIp in the cornea could also be considered. We suggest that future development of TGFBI-linked corneal dystrophy animal models should consider these factors.

\subsection{Future treatment options}

\subsubsection{The use of CRISPR/Cas9 for the treatment of inherited disease}

The clustered regularly interspaced short palindromic repeats (CRISPR)/CRISPR-associated protein 9 (Cas9) system has shown great promise for applications in gene correction therapy. A CRISPR gene editing technique has been approved by the National Institutes of Health in the USA to help extend cancer therapies that rely on enlisting 
a patient's T cells. Early in 2018, doctors at the University of Pennsylvania were in the final steps of preparing for a clinical trial, and in 2019, two cancer patients who were enrolled in this study were treated. This trial is small and designed to investigate whether CRISPR is safe for use in people. It is one study among many that is being undertaken in a clinical setting.

Inherited diseases where a causative genetic mutation has been established are well suited for gene editing therapies such as CRISPR/Cas9. One such disease, hemophilia B, caused by an X-linked mutation, has been studied extensively in this regard. The results from two CRISPR/Cas9-mediated gene correction therapy approaches, in vivo in a hemophilia B mouse model engineered to imitate human disease and ex vivo in germline cells, supported CRISPR/Cas9-mediated genome editing as a feasible method for gene therapy of genetic disorders (Huai et al., 2017). The use of CRISPR is also under development for treating inherited ocular diseases (Burnight et al., 2018; Lee et al., 2019). Editas Medicine and Allergan Pharmaceuticals International Limited plan to initiate patient screening for clinical trials to test the efficacy of EDIT-101, a CRISPR genome-editing drug for the treatment of the retinal disease Leber congenital amaurosis 10. Utilizing an AAV5 viral vector that encodes the Staphylococcus aureus Cas 9 along with two different guide RNAs targeted to either side of the IVS26 mutation between exon 26 and exon 27, EDIT-101 plans to delete or invert the mutation such that functional CEP290 expression is restored. Recently, published results detail the development of EDIT-101 and summarize in vitro experiments in human cells and retinal explants (Maeder et al., 2019).

\subsubsection{CRISPR/Cas9 gene editing for TGFBI-linked corneal dystrophies}

\subsubsection{Corneal autosomal dominant genetic eye disease - allele specificity}

TGFBI-linked corneal dystrophies are the result of autosomal dominant inheritance patterns (Klintworth, 2009). They are predominantly monogenic and highly penetrant, making them ideal for applying the concepts of personalized medicine in genome-editing therapies (Moore et al., 2018). Subsequently, research into the use of CRISPR/Cas9 for the treatment of rare inherited corneal disease has rapidly progressed over the past few years. We were the first to demonstrate an allele-specific CRISPR/Cas9 approach, cleaving the mutant DNA at a single nucleotide polymorphism (SNP)-derived protospacer adjacent motif (PAM) in the Krt12 gene within the mouse cornea (Courtney et al., 2016). For this approach, we took advantage of the discriminating nature of the PAM, which acts as a recognition site for the Cas enzyme, requiring a precise sequence composition. The base composition of the PAM site is crucial for double-stranded breaks to occur. When a DNA mutation or SNP known to cause disease also creates a PAM where none existed before, this mutation can be exploited to precisely target the mutant allele with the CRISPR/Cas system. In this study, a disease-causing missense mutation generating a novel PAM site was found to exist for Meesmann's epithelial corneal dystrophy within the KRT12 gene (Courtney et al., 2016). Meesmann's epithelial corneal dystrophy most commonly occurs as an autosomal dominant genetic disease, and 
we were able to knock down the mutant allele via nonhomologous end joining while leaving the wild-type allele intact. This approach of allele-specific gene editing is an option to treat TGFBI-linked corneal dystrophy caused by dominant negative missense mutations that generate novel PAMs.

As shown in Table 2, 63 known missense mutations located in the coding region of the TGFBI gene can lead to various forms of TGFBI-linked corneal dystrophies. However, the vast majority of cases are due to 5 prevalent mutations found either in codon 124 on exon 4 or codon 555 on exon 12 (Poulaki and Colby, 2008). Since at least 44 of the known mutations in TGFBI occur adjacent to a naturally occurring PAM, stringent fidelity is required to achieve complete allele specificity and avoid the off-target site that exists in the form of the wild-type allele for these mutations (Christie et al., 2017). Studies have demonstrated that truncating the single guide RNA leads to increased target specificity and reduced target activity (Fu et al., 2014a; Fu et al., 2014b; Pattanayak et al., 2013). However, it has been shown by us that a range of truncated guide lengths or addition of 5'-GG to the 20 nucleotide guide sequence did not provide a marked improvement of specificity for a subgroup of the TGFBI mutations (Christie et al., 2017).

\subsubsection{Mutant allele targeting, a dual cut approach}

Given that over $30 \%$ of the known mutations in the TGFBI gene that cause corneal dystrophy are not located in the vicinity of a naturally occurring PAM, it is not possible to design allele-specific single guide RNAs targeted to these mutations. We have therefore conceived of a dual cut approach that, in theory, would achieve knockdown for all TGFBI missense mutations applicable to heterozygous genotypes (unpublished results). With a dual cut approach, the treatment of autosomal dominant disease such as TGFBI-linked corneal dystrophy is not constrained by the specific mutation responsible for any given phenotype. Our approach utilizes naturally occurring variants in the target region characterized by SNP-derived PAMs, which allow for the design of allele-specific SNP-derived PAM single guide RNAs. Utilizing natural variants in the target region that harbor a PAM that lies in cis with the causative mutation allows this method to discriminate between the wild-type and mutant alleles. Premature termination of translation via nonhomologous end joining brings about a permanent disruption of the target gene. A dual guide approach to CRISPR/Cas9 editing was shown to be a promising therapeutic approach for the treatment of patients with Leber congenital amaurosis 10 bearing the CEP290 splice mutation (Ruan et al., 2017), and in a human cell line, it was demonstrated that DNA deletions up to $10 \mathrm{~kb}$ coupled to precise nonhomologous end joining effectively knocked down a mutant allele (Zheng et al., 2014). To generate a therapeutic outcome for the TGFBI mutation targeted in our work, an in cis dual guide approach was required (unpublished results).

While our study focused on the issue of on-target allele specificity in relation to TGFBI-linked corneal dystrophies (unpublished results), for translation to the clinic, a number of key hurdles will need to be overcome, including genome-wide specificity and efficiency of delivery to the correct cells in the cornea. Potent targeting of the correct cell population must be achieved. In corneal tissue, the majority of TGFBIp is produced in the epithelium, and the 
epithelium is continually turned over and repopulated by limbal epithelial stem cells. Thus, to permanently correct the TGFBI-linked corneal dystrophies, efficient delivery to the limbal epithelial stem cells must be achieved. As we enter into the era of personalized genome editing for meaningful therapeutic outcomes to be achieved, we are ever mindful of hurdles such as efficiency and drug delivery.

\subsubsection{Anti-fibrillating agents}

Provided the significant advances in our understanding of the mechanisms leading to fibrillation of TGFBIp and FAS1-4, multiple pharmaceutical strategies to prevent this process present themselves as complements to the far more invasive and temporary strategy of corneal transplantation. Given that LCD mutants attain their phenotype by increasing the population of the unfolded state, a possible approach is to stabilize the native state, in particular, the FAS1-4 domain. Thus, any ligand that preferentially binds to the native state will inherently stabilize this species at the expense of the unfolded state for simple mass-action reasons. The attractive feature of any such intervention is the accessibility of the cornea, making regular applications in the form of eye drops straightforward and uncomplicated. The challenge is to develop or identify such ligands. The structure of FAS1-4 does not present any apparent clefts or other surface irregularities, which could serve as a starting point for drug design, but fortunately, several approaches are available that do not rely on these preconditions. One option is fragment-based design based on screening of binding a representative number of small molecule binders to, e.g., immobilized FAS1-4 using surface plasmon resonance. Alternatively, phage display could lead to the identification of promising peptide leads. Such binding sites have to be preferably directed at the mutation-free sites on FAS1-4 to ensure that all LCD sites are targeted; this problem will be relatively insignificant since most LCD mutations are buried. In contrast, ligands for GCD mutations have to target the offending (and exposed) mutation site to prevent the decrease in solubility that leads to aggregation of these mutants. An alternative approach is to disrupt the aggregation mechanism using "universal" aggregation inhibitors such as the plant polyphenol epigallocatechin. Epigallocatechin has been shown to generate small oligomers of the LCD mutant A546T (Stenvang et al., 2016) and to remodel existing A546T amyloid deposits into protease-sensitive amorphous aggregates that presumably could be cleared by the cornea's own protein quality machinery. While the efficiency of epigallocatechin diffusion into the eye is unknown, epigallocatechin is nontoxic to rat primary epithelial cells (Cia et al., 2014), making it a promising candidate, though additional in vivo experiments are required to establish the validity of this approach.

\section{Future directions and conclusions}

TGFBIp is a versatile ECM protein expressed throughout the human body, with a particularly high abundance in the cornea. Much still remains to be discovered about the functions of TGFBIp, and although many ECM components interact with TGFBIp, the precise roles of these interactions need to be elucidated. Interestingly, $60 \%$ 
of TGFBIp is bound to collagen XII in the human cornea through a disulfide bridge. However, the formation, regulation, and function of this crosslink is not well understood. In addition, it is unknown why TGFBIp is extensively processed in the cornea and which proteases are responsible for the processing.

To date, 74 mutations in TGFBI have been associated with TGFBI-linked corneal dystrophies. Remarkably, these different mutations in TGFBIp can lead to a range of distinct clinical outcomes with a high genotype-phenotype correlation. Several studies have investigated the biochemical mechanisms that lead to protein aggregation. In the case of GCD, TBCD, and RBCD, we propose that the solubility of TGFBIp is reduced and/or the interplay between TGFBIp and the extracellular milieu is disturbed, while LCD is most likely linked to a change in the proteolytic processing of TGFBIp possibly by the serine protease HtrA1. These mechanisms must be investigated more extensively in vivo. The key to test this and future therapeutics is a good model system; hence, significant efforts have to be put into development of animal models with high resemblance to the disease manifestation in humans.

The widened understanding of the biochemical mechanisms of TGFBIp aggregation might facilitate the development of topical agents capable of dissolving and/or inhibiting the formation of mutant TGFBIp aggregates in the cornea. These might include small molecule binders or peptides that stabilize LCD mutants or prevent the decrease in solubility of GCD mutants. Alternatively, "universal" aggregation inhibitors such as plant polyphenol epigallocatechin is a promising candidate. However, the efficiency, safety, and delivery of these agents need to be tested in in vivo.

In addition, as personalized genome editing becomes more routinely used, the CRISPR/Cas 9 technique will be an obvious choice for the treatment of TGFBI-linked corneal dystrophies. The dual cut approach would be a promising strategy for the treatment of a range of heterozygous genotypes. However, this approach leads to a disruption of the target gene, and any effects of a lower level of TGFBIp expression should be considered. In addition, genome-wide specificity and efficient delivery to the cornea needs to be obtained for translation to the clinic.

\section{Disclosure}

Connie Chao-Shern and Dr. Larry DeDionisio are employees of Avellino Labs USA. Professor Tara Moore is a consultant for Avellino Labs USA. The remaining authors have no disclosures to declare.

\section{Acknowledgments}

This work was supported by the VELUX Foundation, the LEO Foundation and the Danish Council for Independent Research. 


\section{References}

Afshari, N.A., Bahadur, R.P., Eifrig, D.E., Jr., Thøgersen, I.B., Enghild, J.J., Klintworth, G.K., 2008. Atypical asymmetric lattice corneal dystrophy associated with a novel homozygous mutation (Val624Met) in the TGFBI gene. Mol Vis 14, 495-499.

Afshari, N.A., Mullally, J.E., Afshari, M.A., Steinert, R.F., Adamis, A.P., Azar, D.T., Talamo, J.H., Dohlman, C.H., Dryja, T.P., 2001. Survey of patients with granular, lattice, avellino, and Reis-Bucklers corneal dystrophies for mutations in the BIGH3 and gelsolin genes. Arch Ophthalmol 119, 16-22.

Ahlfeld, S.K., Wang, J., Gao, Y., Snider, P., Conway, S.J., 2016. Initial Suppression of Transforming Growth Factorbeta Signaling and Loss of TGFBI Causes Early Alveolar Structural Defects Resulting in Bronchopulmonary Dysplasia. Am J Pathol 186, 777-793.

Aldave, A.J., Rayner, S.A., Kim, B.T., Prechanond, A., Yellore, V.S., 2006. Unilateral lattice corneal dystrophy associated with the novel His572del mutation in the TGFBI gene. Mol Vis 12, 142-146.

Aldave, A.J., Sonmez, B., Forstot, S.L., Rayner, S.A., Yellore, V.S., Glasgow, B.J., 2007. A clinical and histopathologic examination of accelerated TGFBIp deposition after LASIK in combined granular-lattice corneal dystrophy. Am J Ophthalmol 143, 416-419.

Aldave, A.J., Yellore, V.S., Sonmez, B., Bourla, N., Salem, A.K., Khan, M.A., Rayner, S.A., Glasgow, B.J., 2008. A novel variant of combined granular-lattice corneal dystrophy associated with the Met619Lys mutation in the TGFBI gene. Arch Ophthalmol 126, 371-377.

Amano, S., Kashiwabuchi, K., Sakisaka, T., Inoue, K., Toda, I., Tsubota, K., 2016. Efficacy of Hyperopic Photorefractive Keratectomy Simultaneously Performed With Phototherapeutic Keratectomy for Decreasing Hyperopic Shift. Cornea 35, 1069-1072.

Andersen, R.B., Karring, H., Møller-Pedersen, T., Valnickova, Z., Thøgersen, I.B., Hedegaard, C.J., Kristensen, T., Klintworth, G.K., Enghild, J.J., 2004. Purification and structural characterization of transforming growth factor beta induced protein (TGFBIp) from porcine and human corneas. Biochemistry 43, 16374-16384.

Andreasen, M., Nielsen, S.B., Runager, K., Christiansen, G., Nielsen, N.C., Enghild, J.J., Otzen, D.E., 2012.

Polymorphic fibrillation of the destabilized fourth fasciclin-1 domain mutant A546T of the Transforming growth factor-beta-induced protein (TGFBIp) occurs through multiple pathways with different oligomeric intermediates. J Biol Chem 287, 34730-34742.

Ann, L.B., Abbouda, A., Frausto, R.F., Huseynli, S., Gupta, K., Alio, J.L., Aldave, A.J., 2017. Variant lattice corneal dystrophy associated with compound heterozygous mutations in the TGFBI gene. $\mathrm{Br} J$ Ophthalmol 101, 509-513. Annis, D.S., Ma, H.Q., Balas, D.M., Kumfer, K.T., Sandbo, N., Potts, G.K., Coon, J.J., Mosher, D.F., 2015. Absence of Vitamin K-Dependent gamma-Carboxylation in Human Periostin Extracted from Fibrotic Lung or Secreted from a Cell Line Engineered to Optimize gamma-Carboxylation. Plos One 10.

Anwar, M., Teichmann, K.D., 2002. Big-bubble technique to bare Descemet's membrane in anterior lamellar keratoplasty. J Cataract Refract Surg 28, 398-403.

Atchaneeyasakul, L.O., Appukuttan, B., Pingsuthiwong, S., Yenchitsomanus, P.T., Trinavarat, A., Srisawat, C., Study, G., 2006. A novel H572R mutation in the transforming growth factor-beta-induced gene in a Thai family with lattice corneal dystrophy type I. Jpn J Ophthalmol 50, 403-408.

Ayres, B.D., Hammersmith, K.M., Laibson, P.R., Rapuano, C.J., 2006. Phototherapeutic keratectomy with intraoperative mitomycin $C$ to prevent recurrent anterior corneal pathology. Am J Ophthalmol 142, 490-492. Bae, J.S., Lee, S.H., Kim, J.E., Choi, J.Y., Park, R.W., Park, J.Y., Park, H.S., Sohn, Y.S., Lee, D.S., Lee, E.B., Kim, I.S., 2002. beta ig-h3 supports keratinocyte adhesion, migration, and proliferation through alpha 3 beta 1 integrin. Biochem Bioph Res Co 294, 940-948.

Bae, J.S., Lee, W., Nam, J.O., Kim, J.E., Kim, S.W., Kim, I.S., 2014. Transforming growth factor beta-induced protein promotes severe vascular inflammatory responses. Am J Respir Crit Care Med 189, 779-786.

Banning, C.S., Kim, W.C., Randleman, J.B., Kim, E.K., Stulting, R.D., 2006. Exacerbation of Avellino corneal dystrophy after LASIK in North America. Cornea 25, 482-484. 
Barbaric, I., Miller, G., Dear, T.N., 2007. Appearances can be deceiving: phenotypes of knockout mice. Brief Funct Genomic Proteomic 6, 91-103.

Basaiawmoit, R.V., Oliveira, C.L., Runager, K., Sørensen, C.S., Behrens, M.A., Jonsson, B.H., Kristensen, T., Klintworth, G.K., Enghild, J.J., Pedersen, J.S., Otzen, D.E., 2011. SAXS models of TGFBIp reveal a trimeric structure and show that the overall shape is not affected by the Arg124His mutation. J Mol Biol 408, 503-513.

Bian, Y.Y., Song, C.X., Cheng, K., Dong, M.M., Wang, F.J., Huang, J.F., Sun, D.G., Wang, L.M., Ye, M.L., Zou, H.F., 2014. An enzyme assisted RP-RPLC approach for in-depth analysis of human liver phosphoproteome. J Proteomics 96, 253-262.

Billings, P.C., Whitbeck, J.C., Adams, C.S., Abrams, W.R., Cohen, A.J., Engelsberg, B.N., Howard, P.S., Rosenbloom, J., 2002. The transforming growth factor-beta-inducible matrix protein (beta)ig-h3 interacts with fibronectin. J Biol Chem 277, 28003-28009.

Borderie, V.M., Sandali, O., Bullet, J., Gaujoux, T., Touzeau, O., Laroche, L., 2012. Long-term results of deep anterior lamellar versus penetrating keratoplasty. Ophthalmology 119, 249-255.

Buckhaults, P., Rago, C., St Croix, B., Romans, K.E., Saha, S., Zhang, L., Vogelstein, B., Kinzler, K.W., 2001. Secreted and cell surface genes expressed in benign and malignant colorectal tumors. Cancer Res 61, 6996-7001.

Burnight, E.R., Giacalone, J.C., Cooke, J.A., Thompson, J.R., Bohrer, L.R., Chirco, K.R., Drack, A.V., Fingert, J.H., Worthington, K.S., Wiley, L.A., Mullins, R.F., Stone, E.M., Tucker, B.A., 2018. CRISPR-Cas9 genome engineering: Treating inherited retinal degeneration. Prog Retin Eye Res 65, 28-49.

Bustamante, M., Tasinato, A., Maurer, F., Elkochairi, I., Lepore, M.G., Arsenijevic, Y., Pedrazzini, T., Munier, F.L., Schorderet, D.F., 2008. Overexpression of a mutant form of TGFBI/BIGH3 induces retinal degeneration in transgenic mice. Mol Vis 14, 1129-1137.

Cao, W.P., Yuan, H.G., Liu, P., Li, X., Hu, Q., 2017. Two mutations in the transforming growth factor beta-induced gene associated with familial Lattice corneal dystrophy. Int J Ophthalmol 10, 343-347.

Chae, H., Kim, M., Kim, Y., Kim, J., Kwon, A., Choi, H., Park, J., Jang, W., Lee, Y.S., Park, S.H., Kim, M.S., 2016.

Mutational spectrum of Korean patients with corneal dystrophy. Clin Genet 89, 678-689.

Chakravarthi, S.V., Kannabiran, C., Sridhar, M.S., Vemuganti, G.K., 2005. TGFBI gene mutations causing lattice and granular corneal dystrophies in Indian patients. Invest Ophthalmol Vis Sci 46, 121-125.

Chao-Shern, C., DeDionisio, L.A., Jang, J.H., Chan, C.C., Thompson, V., Christie, K., Nesbit, M.A., McMullen, C.B.T., 2019. Evaluation of TGFBI corneal dystrophy and molecular diagnostic testing. Eye (Lond) 33, 874-881.

Chao-Shern, C., Me, R., DeDionisio, L.A., Ke, B.L., Nesbit, M.A., Marshall, J., Moore, C.B.T., 2018. Post-LASIK exacerbation of granular corneal dystrophy type 2 in members of a chinese family. Eye (Lond) 32, 39-43. Chiu, E.K., Lin, A.Y., Folberg, R., Saidel, M., 2007. Avellino dystrophy in a patient after laser-assisted in situ keratomileusis surgery manifesting as granular dystrophy. Arch Ophthalmol 125, 703-705.

Cho, K.J., Mok, J.W., Na, K.S., Rho, C.R., Byun, Y.S., Hwang, H.S., Hwang, K.Y., Joo, C.K., 2012. TGFBI gene mutations in a Korean population with corneal dystrophy. Mol Vis 18, 2012-2021.

Choi, S.I., Maeng, Y.S., Kim, T.I., Lee, Y., Kim, Y.S., Kim, E.K., 2015. Lysosomal trafficking of TGFBIp via caveolaemediated endocytosis. PLoS One 10, e0119561.

Choi, T., Huang, M., Gorman, C., Jaenisch, R., 1991. A generic intron increases gene expression in transgenic mice. Mol Cell Biol 11, 3070-3074.

Christensen, L.F., Malmos, K.G., Christiansen, G., Otzen, D.E., 2016. A Complex Dance: The Importance of Glycosaminoglycans and Zinc in the Aggregation of Human Prolactin. Biochemistry 55, 3674-3684.

Christie, K.A., Courtney, D.G., DeDionisio, L.A., Shern, C.C., De Majumdar, S., Mairs, L.C., Nesbit, M.A., Moore, C.B.T., 2017. Towards personalised allele-specific CRISPR gene editing to treat autosomal dominant disorders. Sci Rep 7, 16174.

Cia, D., Vergnaud-Gauduchon, J., Jacquemot, N., Doly, M., 2014. Epigallocatechin gallate (EGCG) prevents H2O2induced oxidative stress in primary rat retinal pigment epithelial cells. Curr Eye Res 39, 944-952.

Cooper, D.N., Mort, M., Stenson, P.D., Ball, E.V., Chuzhanova, N.A., 2010. Methylation-mediated deamination of 5-methylcytosine appears to give rise to mutations causing human inherited disease in CpNpG trinucleotides, as well as in CpG dinucleotides. Hum Genomics 4, 406-410. 
Copeland, R.A., Afshari, N.A., 2013. Copeland and Afshari's Principles and Pratice of Cornea, 1st ed. ed. JaypeeHighlights Medical Publishers, Inc.

Courtney, D.G., Moore, J.E., Atkinson, S.D., Maurizi, E., Allen, E.H., Pedrioli, D.M., McLean, W.H., Nesbit, M.A., Moore, C.B., 2016. CRISPR/Cas9 DNA cleavage at SNP-derived PAM enables both in vitro and in vivo KRT12 mutation-specific targeting. Gene Ther 23, 108-112.

Courtney, D.G., Poulsen, E.T., Kennedy, S., Moore, J.E., Atkinson, S.D., Maurizi, E., Nesbit, M.A., Moore, C.B., Enghild, J.J., 2015. Protein Composition of TGFBI-R124C- and TGFBI-R555W-Associated Aggregates Suggests Multiple Mechanisms Leading to Lattice and Granular Corneal Dystrophy. Invest Ophthalmol Vis Sci 56, 46534661.

Coutu, D.L., Wu, J.H., Monette, A., Rivard, G.E., Blostein, M.D., Galipeau, J., 2008. Periostin, a member of a novel family of vitamin K-dependent proteins, is expressed by mesenchymal stromal cells. Journal of Biological Chemistry 283, 17991-18001.

Dighiero, P., Drunat, S., D'Hermies, F., Renard, G., Delpech, M., Valleix, S., 2000a. A novel variant of granular corneal dystrophy caused by association of 2 mutations in the TGFBI gene-R124L and DeltaT125-DeltaE126. Arch Ophthalmol 118, 814-818.

Dighiero, P., Drunat, S., Ellies, P., D'Hermies, F., Savoldelli, M., Legeais, J.M., Renard, G., Delpech, M., Grateau, G., Valleix, S., 2000b. A new mutation (A546T) of the betaig-h3 gene responsible for a French lattice corneal dystrophy type IIIA. Am J Ophthalmol 129, 248-251.

Doliana, R., Bot, S., Bonaldo, P., Colombatti, A., 2000. EMI, a novel cysteine-rich domain of EMILINs and other extracellular proteins, interacts with the $\mathrm{gClq}$ domains and participates in multimerization. FEBS Lett 484, 164168.

Dudakova, L., Palos, M., Jirsova, K., Skalicka, P., Dundr, P., Liskova, P., 2016. Novel TGFBI mutation p.(Leu558Arg) in a lattice corneal dystrophy patient. Ophthalmic Genet 37, 473-474.

Dyrlund, T.F., Poulsen, E.T., Scavenius, C., Nikolajsen, C.L., Thøgersen, I.B., Vorum, H., Enghild, J.J., 2012. Human cornea proteome: identification and quantitation of the proteins of the three main layers including epithelium, stroma, and endothelium. J Proteome Res 11, 4231-4239.

Eifrig, D.E., Jr., Afshari, N.A., Buchanan, H.W.t., Bowling, B.L., Klintworth, G.K., 2004. Polymorphic corneal amyloidosis: a disorder due to a novel mutation in the transforming growth factor beta-induced (BIGH3) gene. Ophthalmology 111, 1108-1114.

Ellies, P., Renard, G., Valleix, S., Boelle, P.Y., Dighiero, P., 2002. Clinical outcome of eight BIGH3-linked corneal dystrophies. Ophthalmology 109, 793-797.

Endo, S., Nguyen, T.H., Fujiki, K., Hotta, Y., Nakayasu, K., Yamaguchi, T., Ishida, N., Kanai, A., 1999. Leu518Pro mutation of the beta ig-h3 gene causes lattice corneal dystrophy type I. Am J Ophthalmol 128, 104-106. Escribano, J., Hernando, N., Ghosh, S., Crabb, J., Coca-Prados, M., 1994. cDNA from human ocular ciliary epithelium homologous to beta ig-h3 is preferentially expressed as an extracellular protein in the corneal epithelium. J Cell Physiol 160, 511-521.

Evans, C.J., Davidson, A.E., Carnt, N., Rojas Lopez, K.E., Veli, N., Thaung, C.M., Tuft, S.J., Hardcastle, A.J., 2016. Genotype-Phenotype Correlation for TGFBI Corneal Dystrophies Identifies p.(G623D) as a Novel Cause of Epithelial Basement Membrane Dystrophy. Invest Ophthalmol Vis Sci 57, 5407-5414.

Fagerholm, P., 2003. Phototherapeutic keratectomy: 12 years of experience. Acta Ophthalmol Scand 81, 19-32. Fagerholm, P., 2016. Outcomes: Recurrence of Disease (Chapter 9) in Corneal Transplantation (Ed. Hjortdal J). Springer International Publishing, Switzerland, 113-128.

Fagerholm, P., Fitzsimmons, T.D., Orndahl, M., Ohman, L., Tengroth, B., 1993. Phototherapeutic keratectomy: long-term results in 166 eyes. Refract Corneal Surg 9, S76-81.

Ferguson, J.W., Thoma, B.S., Mikesh, M.F., Kramer, R.H., Bennett, K.L., Purchio, A., Bellard, B.J., LeBaron, R.G., 2003. The extracellular matrix protein betalG-H3 is expressed at myotendinous junctions and supports muscle cell adhesion. Cell Tissue Res 313, 93-105.

Fogla, R., Knyazer, B., 2014. Microkeratome-assisted two-stage technique of superficial anterior lamellar keratoplasty for Reis-Bucklers corneal dystrophy. Cornea 33, 1118-1122. 
Foja, S., Hoffmann, K., Auw-Haedrich, C., Reinhard, T., Rupprecht, A., Gruenauer-Kloevekorn, C., 2016.

Identification of two novel mutations in the cornea-specific TGFBI gene causing unique phenotypes in patients with corneal dystrophies. Int Ophthalmol 36, 867-873.

Frising, M., Wildhardt, G., Frisch, L., Pitz, S., 2006. Recurrent granular dystrophy of the cornea: an unusual case. Cornea 25, 614-617.

Fu, Y., Reyon, D., Joung, J.K., 2014a. Targeted genome editing in human cells using CRISPR/Cas nucleases and truncated guide RNAs. Methods Enzymol 546, 21-45.

Fu, Y., Sander, J.D., Reyon, D., Cascio, V.M., Joung, J.K., 2014b. Improving CRISPR-Cas nuclease specificity using truncated guide RNAs. Nat Biotechnol 32, 279-284.

Fujiki, K., Hotta, Y., Nakayasu, K., Yokoyama, T., Takano, T., Yamaguchi, T., Kanai, A., 1998. A new L527R mutation of the betalGH3 gene in patients with lattice corneal dystrophy with deep stromal opacities. Hum Genet 103, 286289.

García-Castellanos, R., Nielsen, N.S., Runager, K., Thøgersen, I.B., Lukassen, M.V., Poulsen, E.T., Goulas, T., Enghild, J.J., Gomis-Rüth, F.X., 2017. Structural and Functional Implications of Human Transforming Growth Factor beta-Induced Protein, TGFBIp, in Corneal Dystrophies. Structure 25, 1740-1750 e1742.

Gibson, M.A., Kumaratilake, J.S., Cleary, E.G., 1997. Immunohistochemical and ultrastructural localization of MP78/70 (betaig-h3) in extracellular matrix of developing and mature bovine tissues. J Histochem Cytochem 45, 1683-1696.

Grau, S., Baldi, A., Bussani, R., Tian, X., Stefanescu, R., Przybylski, M., Richards, P., Jones, S.A., Shridhar, V., Clausen, T., Ehrmann, M., 2005. Implications of the serine protease HtrA1 in amyloid precursor protein processing. Proc Natl Acad Sci U S A 102, 6021-6026.

Gruenauer-Kloevekorn, C., Clausen, I., Weidle, E., Wolter-Roessler, M., Tost, F., Volcker, H.E., Schulze, D.P., Heinritz, W., Reinhard, T., Froster, U., Duncker, G., Schorderet, D., Auw-Haedrich, C., 2009. TGFBI (BIGH3) gene mutations in German families: two novel mutations associated with unique clinical and histopathological findings. Br J Ophthalmol 93, 932-937.

Guo, Y.S., Tang, J., Chen, B., Huang, W., Li, Y., Cui, H.Y., Zhang, X., Wang, S.J., Chen, Z.N., Jiang, J.L., 2011. betaig-h3 regulates store-operated $\mathrm{Ca} 2+$ entry and promotes the invasion of human hepatocellular carcinoma cells. Cell Biol Int 35, 811-817.

Ha, B.J., Kim, T.I., Choi, S.I., Stulting, R.D., Lee, D.H., Cho, H.S., Kim, E.K., 2010. Mitomycin C does not inhibit exacerbation of granular corneal dystrophy type II induced by refractive surface ablation. Cornea 29, 490-496. Ha, N.T., Cung le, X., Chau, H.M., Thanh, T.K., Fujiki, K., Murakami, A., Kanai, A., 2003. A novel mutation of the TGFBI gene found in a Vietnamese family with atypical granular corneal dystrophy. Jpn J Ophthalmol 47, 246-248. Han, B., Luo, H., Raelson, J., Huang, J., Li, Y., Tremblay, J., Hu, B., Qi, S., Wu, J., 2014. TGFBI (betalG-H3) is a diabetes-risk gene based on mouse and human genetic studies. Hum Mol Genet 23, 4597-4611.

Han, K.E., Choi, S.I., Kim, T.I., Maeng, Y.S., Stulting, R.D., Ji, Y.W., Kim, E.K., 2016. Pathogenesis and treatments of TGFBI corneal dystrophies. Prog Retin Eye Res 50, 67-88.

Hanssen, E., Reinboth, B., Gibson, M.A., 2003. Covalent and non-covalent interactions of betaig-h3 with collagen VI. Beta ig-h3 is covalently attached to the amino-terminal region of collagen VI in tissue microfibrils. J Biol Chem 278, 24334-24341.

Hashimoto, K., Noshiro, M., Ohno, S., Kawamoto, T., Satakeda, H., Akagawa, Y., Nakashima, K., Okimura, A., Ishida, H., Okamoto, T., Pan, H., Shen, M., Yan, W.Q., Kato, Y., 1997. Characterization of a cartilage-derived 66-kDa protein (RGD-CAP/beta ig-h3) that binds to collagen. Bba-Mol Cell Res 1355, 303-314.

Holden, B.A., Fricke, T.R., Wilson, D.A., Jong, M., Naidoo, K.S., Sankaridurg, P., Wong, T.Y., Naduvilath, T.J., Resnikoff, S., 2016. Global Prevalence of Myopia and High Myopia and Temporal Trends from 2000 through 2050. Ophthalmology 123, 1036-1042.

Hong, J.P., Kim, T.I., Chung, J.L., Huang, D., Cho, H.S., Kim, E.K., 2011. Analysis of deposit depth and morphology in granular corneal dystrophy type 2 using fourier domain optical coherence tomography. Cornea 30, 729-738.

Horiuchi, K., Amizuka, N., Takeshita, S., Takamatsu, H., Katsuura, M., Ozawa, H., Toyama, Y., Bonewald, L.F., Kudo, A., 1999. Identification and characterization of a novel protein, periostin, with restricted expression to periosteum 
and periodontal ligament and increased expression by transforming growth factor beta. J Bone Miner Res 14, 1239-1249.

Huai, C., Jia, C., Sun, R., Xu, P., Min, T., Wang, Q., Zheng, C., Chen, H., Lu, D., 2017. CRISPR/Cas9-mediated somatic and germline gene correction to restore hemostasis in hemophilia B mice. Hum Genet 136, 875-883.

Ivanov, S.V., Ivanova, A.V., Salnikow, K., Timofeeva, O., Subramaniam, M., Lerman, M.I., 2008. Two novel VHL targets, TGFBI (BIGH3) and its transactivator KLF10, are up-regulated in renal clear cell carcinoma and other tumors. Biochem Biophys Res Commun 370, 536-540.

Jun, A.S., Meng, H., Ramanan, N., Matthaei, M., Chakravarti, S., Bonshek, R., Black, G.C., Grebe, R., Kimos, M., 2012. An alpha 2 collagen VIII transgenic knock-in mouse model of Fuchs endothelial corneal dystrophy shows early endothelial cell unfolded protein response and apoptosis. Hum Mol Genet 21, 384-393.

Jun, R.M., Tchah, H., Kim, T.I., Stulting, R.D., Jung, S.E., Seo, K.Y., Lee, D.H., Kim, E.K., 2004. Avellino corneal dystrophy after LASIK. Ophthalmology 111, 463-468.

Jung, J.W., Kim, S.A., Kang, E.M., Kim, T.I., Cho, H.S., Kim, E.K., 2014. Lattice corneal dystrophy type IIIA with hyaline component from a novel A620P mutation and distinct surgical treatments. Cornea 33, 1324-1331. Jurkunas, U.V., Bitar, M., Rawe, I., 2009. Colocalization of increased transforming growth factor-beta-induced protein (TGFBIp) and Clusterin in Fuchs endothelial corneal dystrophy. Invest Ophthalmol Vis Sci 50, 1129-1136. Karring, H., Poulsen, E.T., Runager, K., Thøgersen, I.B., Klintworth, G.K., Højrup, P., Enghild, J.J., 2013. Serine protease HtrA1 accumulates in corneal transforming growth factor beta induced protein (TGFBIp) amyloid deposits. Mol Vis 19, 861-876.

Karring, H., Runager, K., Thøgersen, I.B., Klintworth, G.K., Højrup, P., Enghild, J.J., 2012. Composition and proteolytic processing of corneal deposits associated with mutations in the TGFBI gene. Exp Eye Res 96, 163-170. Karring, H., Runager, K., Valnickova, Z., Thøgersen, I.B., Møller-Pedersen, T., Klintworth, G.K., Enghild, J.J., 2010. Differential expression and processing of transforming growth factor beta induced protein (TGFBIp) in the normal human cornea during postnatal development and aging. Exp Eye Res 90, 57-62.

Kawasaki, S., Yagi, H., Yamasaki, K., Matsuda, A., Takeda, K., Kinoshita, S., 2011. A novel mutation of the TGFBI gene causing a lattice corneal dystrophy with deep stromal involvement. $\mathrm{Br} J$ Ophthalmol 95, 150-151.

Kawashima, M., Kawakita, T., Den, S., Shimmura, S., Tsubota, K., Shimazaki, J., 2006. Comparison of deep lamellar keratoplasty and penetrating keratoplasty for lattice and macular corneal dystrophies. Am J Ophthalmol 142, 304309.

Kheir, V., Cortes-Gonzalez, V., Zenteno, J.C., Schorderet, D.F., 2019. Mutation update: TGFBI pathogenic and likely pathogenic variants in corneal dystrophies. Hum Mutat.

Kim, B.Y., Olzmann, J.A., Choi, S.I., Ahn, S.Y., Kim, T.I., Cho, H.S., Suh, H., Kim, E.K., 2009a. Corneal dystrophyassociated R124H mutation disrupts TGFBI interaction with Periostin and causes mislocalization to the lysosome. J Biol Chem 284, 19580-19591.

Kim, H.J., Kim, I.S., 2008. Transforming growth factor-beta-induced gene product, as a novel ligand of integrin alphaMbeta2, promotes monocytes adhesion, migration and chemotaxis. Int J Biochem Cell Biol 40, 991-1004. Kim, H.J., Kim, P.K., Bae, S.M., Son, H.N., Thoudam, D.S., Kim, J.E., Lee, B.H., Park, R.W., Kim, I.S., $2009 b$. Transforming growth factor-beta-induced protein (TGFBlp/beta ig-h3) activates platelets and promotes thrombogenesis. Blood 114, 5206-5215.

Kim, J.E., Han, M.S., Bae, Y.C., Kim, H.K., Kim, T.I., Kim, E.K., Kim, I.S., 2007. Anterior segment dysgenesis after overexpression of transforming growth factor-beta-induced gene, beta igh3, in the mouse eye. Mol Vis 13, 19421952.

Kim, J.E., Jeong, H.W., Nam, J.O., Lee, B.H., Choi, J.Y., Park, R.W., Park, J.Y., Kim, I.S., 2002a. Identification of motifs in the fasciclin domains of the transforming growth factor-beta-induced matrix protein beta ig-h3 that interact with the alpha v65 integrin. Journal of Biological Chemistry 277, 46159-46165.

Kim, J.E., Kim, E.H., Han, E.H., Park, R.W., Park, I.H., Jun, S.H., Kim, J.C., Young, M.F., Kim, I.S., 2000a. A TGF-betainducible cell adhesion molecule, betaig-h3, is downregulated in melorheostosis and involved in osteogenesis. J Cell Biochem 77, 169-178. 
Kim, J.E., Kim, S.J., Lee, B.H., Park, R.W., Kim, K.S., Kim, I.S., 2000b. Identification of motifs for cell adhesion within the repeated domains of transforming growth factor-beta-induced gene, betaig-h3. J Biol Chem 275, 3090730915.

Kim, J.E., Park, R.W., Choi, J.Y., Bae, Y.C., Kim, K.S., Joo, C.K., Kim, I.S., 2002b. Molecular properties of wild-type and mutant beta IG-H3 proteins. Invest Ophth Vis Sci 43, 656-661.

Kim, M.O., Yun, S.J., Kim, I.S., Sohn, S., Lee, E.H., 2003. Transforming growth factor-beta-inducible gene-h3 (beta(ig)-h3) promotes cell adhesion of human astrocytoma cells in vitro: implication of alpha6beta4 integrin. Neurosci Lett 336, 93-96.

Klintworth, G.K., 2009. Corneal dystrophies. Orphanet J Rare Dis 4, 7.

Klintworth, G.K., Bao, W., Afshari, N.A., 2004. Two mutations in the TGFBI (BIGH3) gene associated with lattice corneal dystrophy in an extensively studied family. Invest Ophthalmol Vis Sci 45, 1382-1388.

Klintworth, G.K., Enghild, J.J., Valnickova, Z., 1994. Discovery of a novel protein (big-h3) in normal human cornea. Invest Ophthalmol Vis Sci 35.

Klintworth, G.K., Valnickova, Z., Enghild, J.J., 1998. Accumulation of beta ig-h3 gene product in corneas with granular dystrophy. Am J Pathol 152, 743-748.

Korvatska, E., Henry, H., Mashima, Y., Yamada, M., Bachmann, C., Munier, F.L., Schorderet, D.F., 2000. Amyloid and non-amyloid forms of 5q31-linked corneal dystrophy resulting from kerato-epithelin mutations at Arg-124 are associated with abnormal turnover of the protein. J Biol Chem 275, 11465-11469.

Korvatska, E., Munier, F.L., Djemai, A., Wang, M.X., Frueh, B., Chiou, A.G., Uffer, S., Ballestrazzi, E., Braunstein, R.E., Forster, R.K., Culbertson, W.W., Boman, H., Zografos, L., Schorderet, D.F., 1998. Mutation hot spots in 5q31linked corneal dystrophies. Am J Hum Genet 62, 320-324.

Lakshminarayanan, R., Chaurasia, S.S., Anandalakshmi, V., Chai, S.M., Murugan, E., Vithana, E.N., Beuerman, R.W., Mehta, J.S., 2014. Clinical and genetic aspects of the TGFBI-associated corneal dystrophies. Ocul Surf 12, 234-251. Lakshminarayanan, R., Vithana, E.N., Chai, S.M., Chaurasia, S.S., Saraswathi, P., Venkatraman, A., Rojare, C., Venkataraman, D., Tan, D., Aung, T., Beuerman, R.W., Mehta, J.S., 2011. A novel mutation in transforming growth factor-beta induced protein (TGFbetalp) reveals secondary structure perturbation in lattice corneal dystrophy. $\mathrm{Br}$ J Ophthalmol 95, 1457-1462.

Lee, B.H., Bae, J.S., Park, R.W., Kim, J.E., Park, J.Y., Kim, I.S., 2006. betaig-h3 triggers signaling pathways mediating adhesion and migration of vascular smooth muscle cells through alphavbeta5 integrin. Exp Mol Med 38, 153-161. Lee, J., Kim, J.H., Lee, D., Chang, J.W., Shin, J.Y., Seo, J.W., Seo, M.H., Moon, N.J., 2018. Long-term clinical outcome of femtosecond laser-assisted lamellar keratectomy with phototherapeutic keratectomy in anterior corneal stromal dystrophy. Br J Ophthalmol 102, 31-36.

Lee, J.H., Cristol, S.M., Kim, W.C., Chung, E.S., Tchah, H., Kim, M.S., Nam, C.M., Cho, H.S., Kim, E.K., 2010. Prevalence of granular corneal dystrophy type 2 (Avellino corneal dystrophy) in the Korean population. Ophthalmic Epidemiol 17, 160-165.

Lee, J.H., Wang, J.H., Chen, J., Li, F., Edwards, T.L., Hewitt, A.W., Liu, G.S., 2019. Gene therapy for visual loss: Opportunities and concerns. Prog Retin Eye Res 68, 31-53.

Lee, J.M., Lee, E.H., Kim, I.S., Kim, J.E., 2015. Tgfbi deficiency leads to a reduction in skeletal size and degradation of the bone matrix. Calcif Tissue Int 96, 56-64.

Lewis, D.R., Price, M.O., Feng, M.T., Price, F.W., Jr., 2017. Recurrence of Granular Corneal Dystrophy Type 1 After Phototherapeutic Keratectomy, Lamellar Keratoplasty, and Penetrating Keratoplasty in a Single Population.

Cornea 36, 1227-1232.

Liao, X., Cui, H., Wang, F., 2013. Establishment of a transgenic mouse model of corneal dystrophy overexpressing human BIGH3. Int J Mol Med 32, 1110-1114.

Lindsley, A., Li, W., Wang, J., Maeda, N., Rogers, R., Conway, S.J., 2005. Comparison of the four mouse fasciclincontaining genes expression patterns during valvuloseptal morphogenesis. Gene Expr Patterns 5, 593-600.

Lisch, W., Weiss, J.S., 2019. Clinical and genetic update of corneal dystrophies. Exp Eye Res 186, 107715.

Liu, J., Zhang, J., Xu, F., Lin, Z., Li, Z., Liu, H., 2018. Structural characterizations of human periostin dimerization and cysteinylation. FEBS Lett 592, 1789-1803. 
Liu, Y., Huang, H., Sun, G., Alwadani, S., Semba, R.D., Lutty, G.A., Yiu, S., Edward, D.P., 2017. Gene Expression Profile of Extracellular Matrix and Adhesion Molecules in the Human Normal Corneal Stroma. Curr Eye Res 42, 520-527.

Lu, J., Qian, J., Izvolsky, K.I., Cardoso, W.V., 2004. Global analysis of genes differentially expressed in branching and non-branching regions of the mouse embryonic lung. Dev Biol 273, 418-435.

Lukassen, M.V., Scavenius, C., Thøgersen, I.B., Enghild, J.J., 2016. Disulfide Bond Pattern of Transforming Growth Factor $\beta$-Induced Protein. Biochemistry 55, 5610-5621.

Ma, C., Rong, Y., Radiloff, D.R., Datto, M.B., Centeno, B., Bao, S., Cheng, A.W., Lin, F., Jiang, S., Yeatman, T.J., Wang, X.F., 2008. Extracellular matrix protein betaig-h3/TGFBI promotes metastasis of colon cancer by enhancing cell extravasation. Genes Dev 22, 308-321.

Ma, J., Cui, W., He, S.M., Duan, Y.H., Heng, L.J., Wang, L., Gao, G.D., 2012. Human U87 astrocytoma cell invasion induced by interaction of betaig-h3 with integrin alpha5beta1 involves calpain-2. PLoS One 7, e37297.

Maeder, M.L., Stefanidakis, M., Wilson, C.J., Baral, R., Barrera, L.A., Bounoutas, G.S., Bumcrot, D., Chao, H., Ciulla, D.M., DaSilva, J.A., Dass, A., Dhanapal, V., Fennell, T.J., Friedland, A.E., Giannoukos, G., Gloskowski, S.W., Glucksmann, A., Gotta, G.M., Jayaram, H., Haskett, S.J., Hopkins, B., Horng, J.E., Joshi, S., Marco, E., Mepani, R., Reyon, D., Ta, T., Tabbaa, D.G., Samuelsson, S.J., Shen, S., Skor, M.N., Stetkiewicz, P., Wang, T., Yudkoff, C., Myer, V.E., Albright, C.F., Jiang, H., 2019. Development of a gene-editing approach to restore vision loss in Leber congenital amaurosis type 10. Nat Med 25, 229-233.

Malmos, K.G., Bjerring, M., Jessen, C.M., Nielsen, E.H.T., Poulsen, E.T., Christiansen, G., Vosegaard, T., Skrydstrup, T., Enghild, J.J., Pedersen, J.S., Otzen, D.E., 2017a. How glycosaminoglycans promote fibrillation of salmon calcitonin. J Biol Chem 292, 15992.

Malmos, K.G., Otzen, D.E., 2014. Glycosaminoglycans and fibrillar polymorphism, in: Lyubchenko, Y.U., V.N. (Ed.), Bionanoimaging: insights into protein misfolding and aggregation. Elsevier/Academic Press, pp. 281-290.

Malmos, K.G., Stenvang, M., Sahin, C., Christiansen, G., Otzen, D.E., 2017b. The Changing Face of Aging: Highly Sulfated Glycosaminoglycans Induce Amyloid Formation in a Lattice Corneal Dystrophy Model Protein. J Mol Biol 429, 2755-2764.

Mashima, Y., Yamamoto, S., Inoue, Y., Yamada, M., Konishi, M., Watanabe, H., Maeda, N., Shimomura, Y., Kinoshita, S., 2000. Association of autosomal dominantly inherited corneal dystrophies with BIGH3 gene mutations in Japan. Am J Ophthalmol 130, 516-517.

Massoudi, D., Malecaze, F., Galiacy, S.D., 2016. Collagens and proteoglycans of the cornea: importance in transparency and visual disorders. Cell Tissue Res 363, 337-349.

Moore, C.B.T., Christie, K.A., Marshall, J., Nesbit, M.A., 2018. Personalised genome editing - The future for corneal dystrophies. Prog Retin Eye Res 65, 147-165.

Mosher, D.F., Johansson, M.W., Gillis, M.E., Annis, D.S., 2015. Periostin and TGF-beta-induced protein: Two peas in a pod? Crit Rev Biochem Mol Biol 50, 427-439.

Munier, F.L., Frueh, B.E., Othenin-Girard, P., Uffer, S., Cousin, P., Wang, M.X., Heon, E., Black, G.C., Blasi, M.A., Balestrazzi, E., Lorenz, B., Escoto, R., Barraquer, R., Hoeltzenbein, M., Gloor, B., Fossarello, M., Singh, A.D., Arsenijevic, Y., Zografos, L., Schorderet, D.F., 2002. BIGH3 mutation spectrum in corneal dystrophies. Invest Ophthalmol Vis Sci 43, 949-954.

Munier, F.L., Korvatska, E., Djemai, A., Le Paslier, D., Zografos, L., Pescia, G., Schorderet, D.F., 1997. Keratoepithelin mutations in four 5q31-linked corneal dystrophies. Nat Genet 15, 247-251.

Murphy-Ullrich, J.E., Sage, E.H., 2014. Revisiting the matricellular concept. Matrix Biol 37, 1-14.

Musch, D.C., Niziol, L.M., Stein, J.D., Kamyar, R.M., Sugar, A., 2011. Prevalence of corneal dystrophies in the United States: estimates from claims data. Invest Ophthalmol Vis Sci 52, 6959-6963.

Nam, E.J., Sa, K.H., You, D.W., Cho, J.H., Seo, J.S., Han, S.W., Park, J.Y., Kim, S.I., Kyung, H.S., Kim, I.S., Kang, Y.M., 2006. Up-regulated transforming growth factor beta-inducible gene $h 3$ in rheumatoid arthritis mediates adhesion and migration of synoviocytes through alpha $v$ beta3 integrin: Regulation by cytokines. Arthritis Rheum 54, 27342744. 
Nam, J.O., Kim, J.E., Jeong, H.W., Lee, S.J., Lee, B.H., Choi, J.Y., Park, R.W., Park, J.Y., Kim, I.S., 2003. Identification of the alphavbeta3 integrin-interacting motif of betaig-h3 and its anti-angiogenic effect. J Biol Chem 278, 2590225909.

Nema, H., Nema, N., 2018. Gems of Ophthalmology Cornea and Sclera, 1st ed. ed. Jaypee-Highlights Medical Publishers, Inc.

Niel-Butschi, F., Kantelip, B., Iwaszkiewicz, J., Zoete, V., Boimard, M., Delpech, M., Bourges, J.L., Renard, G., D'Hermies, F., Pisella, P.J., Hamel, C., Delbosc, B., Valleix, S., 2011. Genotype-phenotype correlations of TGFBI p.Leu509Pro, p.Leu509Arg, p.Val613Gly, and the allelic association of p.Met502Val-p.Arg555Gln mutations. Mol Vis 17, 1192-1202.

Nielsen, N.S., Juhl, D.W., Poulsen, E.T., Lukassen, M.V., Poulsen, E.C., Risor, M.W., Scavenius, C., Enghild, J.J., 2017. Mutation-Induced Deamidation of Corneal Dystrophy-Related Transforming Growth Factor beta-Induced Protein. Biochemistry 56, 6470-6480.

Nielsen, N.S., Poulsen, E.T., Klintworth, G.K., Enghild, J.J., 2014. Insight into the Protein Composition of Immunoglobulin Light Chain Deposits of Eyelid, Orbital and Conjunctival Amyloidosis. J Proteomics Bioinform Suppl 8.

Nielsen, S.B., Yde, P., Giehm, L., Sundbye, S., Christiansen, G., Mathiesen, J., Jensen, M.H., Jensen, P.H., Otzen, D.E., 2012. Multiple roles of heparin in the aggregation of p25alpha. J Mol Biol 421,601-615.

Norris, R.A., Kern, C.B., Wessels, A., Wirrig, E.E., Markwald, R.R., Mjaatvedt, C.H., 2005. Detection of betaig-H3, a TGFbeta induced gene, during cardiac development and its complementary pattern with periostin. Anat Embryol (Berl) 210, 13-23.

Ohno, S., Doi, T., Fujimoto, K., Ijuin, C., Tanaka, N., Tanimoto, K., Honda, K., Nakahara, M., Kato, Y., Tanne, K., 2002. RGD-CAP (betaig-h3) exerts a negative regulatory function on mineralization in the human periodontal ligament. J Dent Res 81, 822-825.

Ohno, S., Noshiro, M., Makihira, S., Kawamoto, T., Shen, M., Yan, W., Kawashima-Ohya, Y., Fujimoto, K., Tanne, K., Kato, Y., 1999. RGD-CAP ((beta)ig-h3) enhances the spreading of chondrocytes and fibroblasts via integrin alpha(1)beta(1). Biochim Biophys Acta 1451, 196-205.

Okada, M., Yamamoto, S., Tsujikawa, M., Watanabe, H., Inoue, Y., Maeda, N., Shimomura, Y., Nishida, K., Quantock, A.J., Kinoshita, S., Tano, Y., 1998. Two distinct kerato-epithelin mutations in Reis-Bucklers corneal dystrophy. Am J Ophthalmol 126, 535-542.

Oldak, M., Szaflik, J.P., Sciezynska, A., Udziela, M., Maksym, R.B., Rymgayllo-Jankowska, B., Hofmann-Rummelt, C., Menzel-Severing, J., Ploski, R., Zarnowski, T., Kruse, F.E., Szaflik, J., 2014. Late-onset lattice corneal dystrophy without typical lattice lines caused by a novel mutation in the TGFBI gene. Cornea 33, 294-299.

Pacella, E., Pacella, F., De Paolis, G., Parisella, F.R., Turchetti, P., Anello, G., Cavallotti, C., 2015.

Glycosaminoglycans in the human cornea: age-related changes. Ophthalmol Eye Dis 7, 1-5.

Paliwal, P., Sharma, A., Tandon, R., Sharma, N., Titiyal, J.S., Sen, S., Kaur, P., Dube, D., Vajpayee, R.B., 2010. TGFBI mutation screening and genotype-phenotype correlation in north Indian patients with corneal dystrophies. Mol Vis $16,1429-1438$.

Pampukha, V.M., Kravchenko, S.A., Tereshchenko, F.A., Livshits, L.A., Drozhyna, G.I., 2009. Novel L558P mutation of the TGFBI gene found in Ukrainian families with atypical corneal dystrophy. Ophthalmologica 223, 207-214. Park, S.J., Park, S., Ahn, H.C., Kim, I.S., Lee, B.J., 2004. Conformational resemblance between the structures of integrin-activating pentapetides derived from beta ig-h3 and RGD peptide analogues in a membrane environment. Peptides 25, 199-205.

Pattanayak, V., Lin, S., Guilinger, J.P., Ma, E., Doudna, J.A., Liu, D.R., 2013. High-throughput profiling of off-target DNA cleavage reveals RNA-programmed Cas9 nuclease specificity. Nat Biotechnol 31, 839-843.

Pepys, M.B., Dyck, R.F., de Beer, F.C., Skinner, M., Cohen, A.S., 1979. Binding of serum amyloid P-component (SAP) by amyloid fibrils. Clin Exp Immunol 38, 284-293.

Poepsel, S., Sprengel, A., Sacca, B., Kaschani, F., Kaiser, M., Gatsogiannis, C., Raunser, S., Clausen, T., Ehrmann, M., 2015. Determinants of amyloid fibril degradation by the PDZ protease HTRA1. Nat Chem Biol 11, 862-869.

Poulaki, V., Colby, K., 2008. Genetics of anterior and stromal corneal dystrophies. Semin Ophthalmol 23, 9-17. 
Poulsen, E.T., Dyrlund, T.F., Runager, K., Scavenius, C., Krogager, T.P., Hojrup, P., Thogersen, I.B., Sanggaard, K.W., Vorum, H., Hjortdal, J., Enghild, J.J., 2014a. Proteomics of Fuchs' endothelial corneal dystrophy support that the extracellular matrix of Descemet's membrane is disordered. J Proteome Res 13, 4659-4667.

Poulsen, E.T., Nielsen, N.S., Jensen, M.M., Nielsen, E., Hjortdal, J., Kim, E.K., Enghild, J.J., 2016. LASIK surgery of granular corneal dystrophy type 2 patients leads to accumulation and differential proteolytic processing of transforming growth factor beta-induced protein (TGFBIp). Proteomics 16, 539-543.

Poulsen, E.T., Nielsen, N.S., Scavenius, C., Mogensen, E.H., Risor, M.W., Runager, K., Lukassen, M.V., Rasmussen, C.B., Christiansen, G., Richner, M., Vorum, H., Enghild, J.J., 2019. The serine protease HtrA1 cleaves misfolded transforming growth factor beta-induced protein (TGFBIp) and induces amyloid formation. J Biol Chem 294, 11817-11828.

Poulsen, E.T., Pedersen, K.W., Marzeda, A.M., Enghild, J.J., 2017. Serum Amyloid P Component (SAP) Interactome in Human Plasma Containing Physiological Calcium Levels. Biochemistry 56, 896-902.

Poulsen, E.T., Runager, K., Nielsen, N.S., Lukassen, M.V., Thomsen, K., Snider, P., Simmons, O., Vorum, H., Conway, S.J., Enghild, J.J., 2018. Proteomic profiling of TGFBI-null mouse corneas reveals only minor changes in matrix composition supportive of TGFBI knockdown as therapy against TGFBI-linked corneal dystrophies. FEBS J 285, 101-114.

Poulsen, E.T., Runager, K., Ris $\varnothing r$, M.W., Dyrlund, T.F., Scavenius, C., Karring, H., Praetorius, J., Vorum, H., Otzen, D.E., Klintworth, G.K., Enghild, J.J., 2014b. Comparison of two phenotypically distinct lattice corneal dystrophies caused by mutations in the transforming growth factor beta induced (TGFBI) gene. Proteomics Clin Appl 8, 168177.

Rawe, I.M., Zhan, Q., Burrows, R., Bennett, K., Cintron, C., 1997. Beta-ig. Molecular cloning and in situ hybridization in corneal tissues. Invest Ophthalmol Vis Sci 38, 893-900.

Rayner, S.A., Gallop, J.L., George, A.J., Larkin, D.F., 1998. Distribution of integrins alpha $v$ beta 5 , alpha $v$ beta 3 and alpha $v$ in normal human cornea: possible implications in clinical and therapeutic adenoviral infection. Eye (Lond) 12 ( Pt 2), 273-277.

Reinboth, B., Thomas, J., Hanssen, E., Gibson, M.A., 2006. Beta ig-h3 interacts directly with biglycan and decorin, promotes collagen $\mathrm{VI}$ aggregation, and participates in ternary complexing with these macromolecules. J Biol Chem $281,7816-7824$.

Ris $\varnothing$ r, M.W., Poulsen, E.T., Thomsen, L.R., Dyrlund, T.F., Nielsen, T.A., Nielsen, N.C., Sanggaard, K.W., Enghild, J.J., 2014. The autolysis of human HtrA1 is governed by the redox state of its $\mathrm{N}$-terminal domain. Biochemistry 53 , 3851-3857.

Rozzo, C., Fossarello, M., Galleri, G., Sole, G., Serru, A., Orzalesi, N., Serra, A., Pirastu, M., 1998. A common beta igh3 gene mutation (delta 5540 ) in a large cohort of Sardinian Reis Bucklers corneal dystrophy patients. Mutations in brief no. 180. Online. Hum Mutat 12, 215-216.

Ruan, G.X., Barry, E., Yu, D., Lukason, M., Cheng, S.H., Scaria, A., 2017. CRISPR/Cas9-Mediated Genome Editing as a Therapeutic Approach for Leber Congenital Amaurosis 10. Mol Ther 25, 331-341.

Runager, K., Basaiawmoit, R.V., Deva, T., Andreasen, M., Valnickova, Z., Sørensen, C.S., Karring, H., Thøgersen, I.B., Christiansen, G., Underhaug, J., Kristensen, T., Nielsen, N.C., Klintworth, G.K., Otzen, D.E., Enghild, J.J., 2011. Human phenotypically distinct TGFBI corneal dystrophies are linked to the stability of the fourth FAS1 domain of TGFBIp. J Biol Chem 286, 4951-4958.

Runager, K., Enghild, J.J., Klintworth, G.K., 2008. Focus on molecules: Transforming growth factor beta induced protein (TGFBIp). Exp Eye Res 87, 298-299.

Runager, K., Klintworth, G.K., Karring, H., Enghild, J.J., 2013. The insoluble TGFBIp fraction of the cornea is covalently linked via a disulfide bond to type XII collagen. Biochemistry 52, 2821-2827.

Runyon, S.T., Zhang, Y., Appleton, B.A., Sazinsky, S.L., Wu, P., Pan, B., Wiesmann, C., Skelton, N.J., Sidhu, S.S., 2007. Structural and functional analysis of the PDZ domains of human HtrA1 and HtrA3. Protein Sci 16, 24542471.

Sakimoto, T., Kanno, H., Shoji, J., Kashima, Y., Nakagawa, S., Miwa, S., Sawa, M., 2003. A novel nonsense mutation with a compound heterozygous mutation in TGFBI gene in lattice corneal dystrophy type I. Jpn J Ophthalmol 47, 13-17. 
Sasaki, H., Kobayashi, Y., Nakashima, Y., Moriyama, S., Yukiue, H., Kaji, M., Kiriyama, M., Fukai, I., Yamakawa, Y., Fujii, Y., 2002. Beta IGH3, a TGF-beta inducible gene, is overexpressed in lung cancer. Jpn J Clin Oncol 32, 85-89. Schaefer, M.H., Yang, J.S., Serrano, L., Kiel, C., 2014. Protein conservation and variation suggest mechanisms of cell type-specific modulation of signaling pathways. PLoS Comput Biol 10, e1003659.

Schmitt-Bernard, C.F., Chavanieu, A., Derancourt, J., Arnaud, B., Demaille, J.G., Calas, B., Argiles, A., 2000a. In vitro creation of amyloid fibrils from native and Arg124Cys mutated betalGH3((110-131)) peptides, and its relevance for lattice corneal amyloid dystrophy type I. Biochem Biophys Res Commun 273, 649-653.

Schmitt-Bernard, C.F., Guittard, C., Arnaud, B., Demaille, J., Argiles, A., Claustres, M., Tuffery-Giraud, S., 2000b. BIGH3 exon 14 mutations lead to intermediate type I/IIIA of lattice corneal dystrophies. Invest Ophthalmol Vis Sci 41, 1302-1308.

Schneider, D., Kleeff, J., Berberat, P.O., Zhu, Z., Korc, M., Friess, H., Buchler, M.W., 2002. Induction and expression of betaig-h3 in pancreatic cancer cells. Biochim Biophys Acta 1588, 1-6.

Schorderet, D.F., Menasche, M., Morand, S., Bonnel, S., Buchillier, V., Marchant, D., Auderset, K., Bonny, C., Abitbol, M., Munier, F.L., 2000. Genomic characterization and embryonic expression of the mouse Bigh3 (Tgfbi) gene. Biochem Biophys Res Commun 274, 267-274.

Seitz, B., Lisch, W., 2011. Stage-related therapy of corneal dystrophies. Dev Ophthalmol 48, 116-153.

Semba, R.D., Enghild, J.J., Venkatraman, V., Dyrlund, T.F., Van Eyk, J.E., 2013. The Human Eye Proteome Project: perspectives on an emerging proteome. Proteomics 13, 2500-2511.

Shao, G., Berenguer, J., Borczuk, A.C., Powell, C.A., Hei, T.K., Zhao, Y., 2006. Epigenetic inactivation of Betaig-h3 gene in human cancer cells. Cancer Res 66, 4566-4573.

Shelton, L., Rada, J.A., 2009. Inhibition of human scleral fibroblast cell attachment to collagen type I by TGFBIp. Invest Ophthalmol Vis Sci 50, 3542-3552.

Siebelmann, S., Scholz, P., Sonnenschein, S., Bachmann, B., Matthaei, M., Cursiefen, C., Heindl, L.M., 2018.

Anterior segment optical coherence tomography for the diagnosis of corneal dystrophies according to the IC3D classification. Surv Ophthalmol 63, 365-380.

Skonier, J., Bennett, K., Rothwell, V., Kosowski, S., Plowman, G., Wallace, P., Edelhoff, S., Disteche, C., Neubauer, M., Marquardt, H., et al., 1994. beta ig-h3: a transforming growth factor-beta-responsive gene encoding a secreted protein that inhibits cell attachment in vitro and suppresses the growth of $\mathrm{CHO}$ cells in nude mice. DNA Cell Biol 13, 571-584.

Skonier, J., Neubauer, M., Madisen, L., Bennett, K., Plowman, G.D., Purchio, A.F., 1992. cDNA cloning and sequence analysis of beta ig-h3, a novel gene induced in a human adenocarcinoma cell line after treatment with transforming growth factor-beta. DNA Cell Biol 11, 511-522.

Son, H.N., Nam, J.O., Kim, S., Kim, I.S., 2013. Multiple FAS1 domains and the RGD motif of TGFBI act cooperatively to bind alphavbeta3 integrin, leading to anti-angiogenic and anti-tumor effects. Biochim Biophys Acta 1833, 23782388.

Song, J.S., Lim, D.H., Chung, E.S., Chung, T.Y., Ki, C.S., 2015. Mutation Analysis of the TGFBI Gene in Consecutive Korean Patients With Corneal Dystrophies. Ann Lab Med 35, 336-340.

Song, X., Cai, L., Li, Y., Zhu, J., Jin, P., Chen, L., Ma, F., 2014. Identification and characterization of transforming growth factor beta induced gene (TGFBIG) from Branchiostoma belcheri: insights into evolution of TGFBI family. Genomics 103, 147-153.

Song, Y., Sun, M., Wang, N., Zhou, X., Zhao, J., Wang, Q., Chen, S., Deng, Y., Qiu, L., Chen, Y., Aldave, A.J., Zhang, F., 2017. Prevalence of transforming growth factor beta-induced gene corneal dystrophies in Chinese refractive surgery candidates. J Cataract Refract Surg 43, 1489-1494.

Srivastava, O.P., Srivastava, K., 1999. cAMP-dependent phosphorylation of betaig-h3 protein in human corneal endothelial cells. Curr Eye Res 19, 348-357.

Stenvang, M., Christiansen, G., Otzen, D.E., 2016. Epigallocatechin Gallate Remodels Fibrils of Lattice Corneal Dystrophy Protein, Facilitating Proteolytic Degradation and Preventing Formation of Membrane-Permeabilizing Species. Biochemistry 55, 2344-2357. 
Stenvang, M., Schafer, N.P., Malmos, K.G., Perez, A.W., Niembro, O., Sormanni, P., Basaiawmoit, R.V., Christiansen, G., Andreasen, M., Otzen, D.E., 2018. Corneal Dystrophy Mutations Drive Pathogenesis by Targeting TGFBIp Stability and Solubility in a Latent Amyloid-forming Domain. J Mol Biol 430, 1116-1140.

Stewart, H., Black, G.C., Donnai, D., Bonshek, R.E., McCarthy, J., Morgan, S., Dixon, M.J., Ridgway, A.A., 1999a. A mutation within exon 14 of the TGFBI (BIGH3) gene on chromosome $5 q 31$ causes an asymmetric, late-onset form of lattice corneal dystrophy. Ophthalmology 106, 964-970.

Stewart, H.S., Ridgway, A.E., Dixon, M.J., Bonshek, R., Parveen, R., Black, G., 1999b. Heterogeneity in granular corneal dystrophy: identification of three causative mutations in the TGFBI (BIGH3) gene-lessons for corneal amyloidogenesis. Hum Mutat 14, 126-132.

Stix, B., Leber, M., Bingemer, P., Gross, C., Ruschoff, J., Fandrich, M., Schorderet, D.F., Vorwerk, C.K., Zacharias, M., Roessner, A., Rocken, C., 2005. Hereditary lattice corneal dystrophy is associated with corneal amyloid deposits enclosing C-terminal fragments of keratoepithelin. Invest Ophthalmol Vis Sci 46, 1133-1139.

Sørensen, C.S., Runager, K., Scavenius, C., Jensen, M.M., Nielsen, N.S., Christiansen, G., Petersen, S.V., Karring, H., Sanggaard, K.W., Enghild, J.J., 2015. Fibril Core of Transforming Growth Factor Beta-Induced Protein (TGFBIp) Facilitates Aggregation of Corneal TGFBIp. Biochemistry 54, 2943-2956.

Takacs, L., Losonczy, G., Matesz, K., Balogh, I., Sohajda, Z., Toth, K., Fazakas, F., Vereb, G., Berta, A., 2007. TGFBI (BIGH3) gene mutations in Hungary--report of the novel F547S mutation associated with polymorphic corneal amyloidosis. Mol Vis 13, 1976-1983.

Tang, J., Zhou, H.W., Jiang, J.L., Yang, X.M., Li, Y., Zhang, H.X., Chen, Z.N., Guo, W.P., 2007. Betalg-h3 is involved in the HAb18G/CD147-mediated metastasis process in human hepatoma cells. Exp Biol Med (Maywood) 232, 344352.

Thapa, N., Kang, K.B., Kim, I.S., 2005. beta ig-h3 mediates osteoblast adhesion and inhibits differentiation. Bone 36, 232-242.

Tian, X., Fujiki, K., Wang, W., Murakami, A., Xie, P., Kanai, A., Liu, Z., 2005. Novel mutation (V505D) of the TGFBI gene found in a Chinese family with lattice corneal dystrophy, type I. Jpn J Ophthalmol 49, 84-88.

Tian, X., Fujiki, K., Zhang, Y., Murakami, A., Li, Q., Kanai, A., Wang, W., Hao, Y., Ma, Z., 2007. A novel variant lattice corneal dystrophy caused by association of mutation (V625D) in TGFBI gene. Am J Ophthalmol 144, 473-475.

Truebestein, L., Tennstaedt, A., Mönig, T., Krojer, T., Canellas, F., Kaiser, M., Clausen, T., Ehrmann, M., 2011.

Substrate-induced remodeling of the active site regulates human HTRA1 activity. Nat Struct Mol Biol 18, 386-388. Underhaug, J., Kolds $\varnothing$, H., Runager, K., Nielsen, J.T., Sørensen, C.S., Kristensen, T., Otzen, D.E., Karring, H., Malmendal, A., Schiøtt, B., Enghild, J.J., Nielsen, N.C., 2013. Mutation in transforming growth factor beta induced protein associated with granular corneal dystrophy type 1 reduces the proteolytic susceptibility through local structural stabilization. Biochim Biophys Acta 1834, 2812-2822.

Venkatraman, A., Dutta, B., Murugan, E., Piliang, H., Lakshminaryanan, R., Sook Yee, A.C., Pervushin, K.V., Sze, S.K., Mehta, J.S., 2017. Proteomic Analysis of Amyloid Corneal Aggregates from TGFBI-H626R Lattice Corneal Dystrophy Patient Implicates Serine-Protease HTRA1 in Mutation-Specific Pathogenesis of TGFBIp. J Proteome Res 16, 2899-2913.

Vierkotten, S., Muether, P.S., Fauser, S., 2011. Overexpression of HTRA1 leads to ultrastructural changes in the elastic layer of Bruch's membrane via cleavage of extracellular matrix components. PLoS One 6, e22959.

Warren, J.F., Abbott, R.L., Yoon, M.K., Crawford, J.B., Spencer, W.H., Margolis, T.P., 2003. A new mutation (Leu569Arg) within exon 13 of the TGFBI (BIGH3) gene causes lattice corneal dystrophy type I. Am J Ophthalmol 136, 872-878.

Ween, M.P., Lokman, N.A., Hoffmann, P., Rodgers, R.J., Ricciardelli, C., Oehler, M.K., 2011. Transforming growth factor-beta-induced protein secreted by peritoneal cells increases the metastatic potential of ovarian cancer cells. Int J Cancer 128, 1570-1584.

Ween, M.P., Oehler, M.K., Ricciardelli, C., 2012. Transforming growth Factor-Beta-Induced Protein (TGFBI)/(betaig-H3): a matrix protein with dual functions in ovarian cancer. Int J Mol Sci 13, 10461-10477. Weiss, J.S., Møller, H.U., Aldave, A.J., Seitz, B., Bredrup, C., Kivela, T., Munier, F.L., Rapuano, C.J., Nischal, K.K., Kim, E.K., Sutphin, J., Busin, M., Labbe, A., Kenyon, K.R., Kinoshita, S., Lisch, W., 2015. IC3D classification of corneal dystrophies--edition 2. Cornea 34, 117-159. 
Weiss, J.S., Møller, H.U., Lisch, W., Kinoshita, S., Aldave, A.J., Belin, M.W., Kivela, T., Busin, M., Munier, F.L., Seitz, B., Sutphin, J., Bredrup, C., Mannis, M.J., Rapuano, C.J., Van Rij, G., Kim, E.K., Klintworth, G.K., 2008. The IC3D classification of the corneal dystrophies. Cornea 27 Suppl 2, S1-83.

Wen, G., Partridge, M.A., Li, B., Hong, M., Liao, W., Cheng, S.K., Zhao, Y., Calaf, G.M., Liu, T., Zhou, J., Zhang, Z., Hei, T.K., 2011. TGFBI expression reduces in vitro and in vivo metastatic potential of lung and breast tumor cells. Cancer Lett 308, 23-32.

Wieben, E.D., Aleff, R.A., Tosakulwong, N., Butz, M.L., Highsmith, W.E., Edwards, A.O., Baratz, K.H., 2012. A common trinucleotide repeat expansion within the transcription factor 4 (TCF4, E2-2) gene predicts Fuchs corneal dystrophy. PLoS One 7, e49083.

Yam, G.H., Wang, K., Jhanji, V., Choy, K.W., Baum, L., Pang, C.P., 2012. In vitro amyloid aggregate forming ability of TGFBI mutants that cause corneal dystrophies. Invest Ophthalmol Vis Sci 53, 5890-5898.

Yamada, N., Kawamoto, K., Morishige, N., Chikama, T., Nishida, T., Nishioka, M., Okayama, N., Hinoda, Y., 2009. Double mutation (R124H, N544S) of TGFBI in two sisters with combined expression of Avellino and lattice corneal dystrophies. Mol Vis 15, 974-979.

Yamamoto, S., Okada, M., Tsujikawa, M., Shimomura, Y., Nishida, K., Inoue, Y., Watanabe, H., Maeda, N., Kurahashi, H., Kinoshita, S., Nakamura, Y., Tano, Y., 1998. A kerato-epithelin (betaig-h3) mutation in lattice corneal dystrophy type IIIA. Am J Hum Genet 62, 719-722.

Yamazoe, K., Yoshida, S., Yasuda, M., Hatou, S., Inagaki, E., Ogawa, Y., Tsubota, K., Shimmura, S., 2015.

Development of a Transgenic Mouse with R124H Human TGFBI Mutation Associated with Granular Corneal Dystrophy Type 2. PLoS One 10, e0133397.

Yang, J., Han, X., Huang, D., Yu, L., Zhu, Y., Tong, Y., Zhu, B., Li, C., Weng, M., Ma, X., 2010. Analysis of TGFBI gene mutations in Chinese patients with corneal dystrophies and review of the literature. Mol Vis 16, 1186-1193. Yoo, S.H., Kymionis, G.D., Koreishi, A., Ide, T., Goldman, D., Karp, C.L., O'Brien, T.P., Culbertson, W.W., Alfonso, E.C., 2008. Femtosecond laser-assisted sutureless anterior lamellar keratoplasty. Ophthalmology 115, 1303-1307, 1307 e1301.

Yu, H., Wergedal, J.E., Zhao, Y., Mohan, S., 2012. Targeted disruption of TGFBI in mice reveals its role in regulating bone mass and bone size through periosteal bone formation. Calcif Tissue Int 91, 81-87.

Yu, P., Gu, Y., Yang, Y., Yan, X., Chen, L., Ge, Z., Qi, M., Si, J., Guo, L., 2006. A clinical and molecular-genetic analysis of Chinese patients with lattice corneal dystrophy and novel Thr538Pro mutation in the TGFBI (BIGH3) gene. J

Genet 85, 73-76.

Yuan, C., Berscheit, H.L., Huang, A.J., 2007. Identification of an amyloidogenic region on keratoepithelin via synthetic peptides. FEBS Lett 581, 241-247.

Yun, S.J., Kim, M.O., Kim, S.O., Park, J., Kwon, Y.K., Kim, I.S., Lee, E.H., 2002. Induction of TGF-beta-inducible geneh3 (betaig-h3) by TGF-beta1 in astrocytes: implications for astrocyte response to brain injury. Brain Res Mol Brain Res 107, 57-64.

Zajchowski, D.A., Bartholdi, M.F., Gong, Y., Webster, L., Liu, H.L., Munishkin, A., Beauheim, C., Harvey, S., Ethier, S.P., Johnson, P.H., 2001. Identification of gene expression profiles that predict the aggressive behavior of breast cancer cells. Cancer Res 61, 5168-5178.

Zamilpa, R., Rupaimoole, R., Phelix, C.F., Somaraki-Cormier, M., Haskins, W., Asmis, R., LeBaron, R.G., 2009. Cterminal fragment of transforming growth factor beta-induced protein (TGFBIp) is required for apoptosis in human osteosarcoma cells. Matrix Biol 28, 347-353.

Zeng, L., Zhao, J., Chen, Y., Zhao, F., Li, M., Chao-Shern, C., Moore, T., Marshall, J., Zhou, X., 2017. TGFBI Gene Mutation Analysis of Clinically Diagnosed Granular Corneal Dystrophy Patients Prior to PTK: A Pilot Study from Eastern China. Sci Rep 7, 596.

Zenteno, J.C., Correa-Gomez, V., Santacruz-Valdez, C., Suarez-Sanchez, R., Villanueva-Mendoza, C., 2009. Clinical and genetic features of TGFBI-linked corneal dystrophies in Mexican population: description of novel mutations and novel genotype-phenotype correlations. Exp Eye Res 89, 172-177.

Zenteno, J.C., Ramirez-Miranda, A., Santacruz-Valdes, C., Suarez-Sanchez, R., 2006. Expanding the mutational spectrum in TGFBI-linked corneal dystrophies: Identification of a novel and unusual mutation (Val113lle) in a family with granular dystrophy. Mol Vis 12, 331-335. 
Zhang, C., Zeng, G., Lin, H., Li, D., Zhao, L., Zhou, N., Qi, Y., 2009a. A novel mutation I522N within the TGFBI gene caused lattice corneal dystrophy I. Mol Vis 15, 2498-2502.

Zhang, J., Wu, D., Li, Y., Fan, Y., Chen, H., Hong, J., Xu, J., 2019. Novel Mutations Associated With Various Types of Corneal Dystrophies in a Han Chinese Population. Front Genet 10, 881.

Zhang, Y., Wen, G., Shao, G., Wang, C., Lin, C., Fang, H., Balajee, A.S., Bhagat, G., Hei, T.K., Zhao, Y., 2009b. TGFBI deficiency predisposes mice to spontaneous tumor development. Cancer Res 69, 37-44.

Zhao, Y.L., Piao, C.Q., Hei, T.K., 2002. Downregulation of Betaig-h3 gene is causally linked to tumorigenic phenotype in asbestos treated immortalized human bronchial epithelial cells. Oncogene 21, 7471-7477.

Zheng, Q., Cai, X., Tan, M.H., Schaffert, S., Arnold, C.P., Gong, X., Chen, C.Z., Huang, S., 2014. Precise gene deletion and replacement using the CRISPR/Cas9 system in human cells. Biotechniques 57, 115-124.

Zhong, X., Chen, S., Huang, W., Yang, J., Chen, X., Zhou, Y., Zhou, Q., Wang, Y., 2010. Novel and known mutations of TGFBI, their genotype-phenotype correlation and structural modeling in 3 Chinese families with lattice corneal dystrophy. Mol Vis 16, 224-230.

Zurawa-Janicka, D., Skorko-Glonek, J., Lipinska, B., 2010. HtrA proteins as targets in therapy of cancer and other diseases. Expert Opin Ther Targets 14, 665-679. 
Table 1.

TGFBIp interaction partners.

\begin{tabular}{|c|c|c|c|}
\hline Protein & & Cell/tissue type & Reference \\
\hline \multicolumn{4}{|c|}{ Integrins } \\
\hline & $\alpha 1 \beta 1$ & Chondrocytes, fibroblasts & (Ohno et al., 1999) \\
\hline & $\alpha \operatorname{llb} \beta 3$ & Platelets & (Kim et al., 2009b) \\
\hline & $\alpha 3 \beta 1$ & Human corneal epithelial cells & (Kim et al., 2000b) \\
\hline & & Keratinocytes & (Bae et al., 2002) \\
\hline & $\alpha 5 \beta 1$ & Platelets & (Kim et al., 2009b) \\
\hline & $\alpha \vee \beta 3$ & Endothelial cells & (Nam et al., 2003; Son et al., 2013) \\
\hline & & Osteoblasts & (Thapa et al., 2005) \\
\hline & & Synoviocytes & (Nam et al., 2006) \\
\hline & & Scleral fibroblasts & (Shelton and Rada, 2009) \\
\hline & & Corneal fibroblasts & (Choi et al., 2015) \\
\hline & $\alpha \vee \beta 5$ & Lung fibroblasts & (Kim et al., 2002a) \\
\hline & & Osteoblasts & (Thapa et al., 2005) \\
\hline & & Vascular smooth muscle cells & (Lee et al., 2006) \\
\hline & & Scleral fibroblasts & (Shelton and Rada, 2009) \\
\hline & $\alpha 6 \beta 4$ & Astrocytoma cells & (Kim et al., 2003) \\
\hline & $\alpha 7 \beta 1$ & Skeletal muscle cells & (Ferguson et al., 2003) \\
\hline & $\alpha M \beta 2$ & Monocytes & (Kim and Kim, 2008) \\
\hline \multicolumn{4}{|c|}{ ECM molecules } \\
\hline & Fibronectin & In vitro & (Billings et al., 2002; Kim et al., 2002b) \\
\hline & Laminin & In vitro & (Kim et al., 2002b) \\
\hline & Decorin & In vitro & (Reinboth et al., 2006) \\
\hline & Biglycan & In vitro & (Reinboth et al., 2006) \\
\hline & Periostin & Human corneal fibroblasts & (Kim et al., 2009a) \\
\hline & Collagen type I & Porcine cartilage & (Hashimoto et al., 1997) \\
\hline & & In vitro & (Billings et al., 2002; Kim et al., 2002b) \\
\hline & Collagen type II & Porcine cartilage & (Hashimoto et al., 1997) \\
\hline & & In vitro & (Kim et al., 2002b) \\
\hline & Collagen type IV & Porcine cartilage & (Hashimoto et al., 1997) \\
\hline & Collagen type VI & Rabbit cornea & (Rawe et al., 1997) \\
\hline
\end{tabular}


Bovine ligament

In vitro

Collagen type XII
Porcine and human cornea
(Hanssen et al., 2003)

(Kim et al., 2002b; Reinboth et al., 2006)

(Runager et al., 2013) 
Table 2

Reported TGFBI mutations associated with TGFBI-linked corneal dystrophies.

\begin{tabular}{|c|c|c|c|c|}
\hline Mutations & Protein domain ${ }^{1}$ & Phenotype $^{2}$ & $\begin{array}{l}\text { Age of onset } \\
\text { (decade) }\end{array}$ & Reference \\
\hline V113I & FAS1-1 & GCD1 & Third & (Zenteno et al., 2006) \\
\hline V113I/L558P & FAS1-1/FAS1-4 & Variant LCD & Fourth - Fifth & (Ann et al., 2017) \\
\hline D123H & FAS1-1 & Atypical GCD & Fifth & (Ha et al., 2003) \\
\hline R124C & FAS1-1 & LCD1 & First - Second & (Munier et al., 1997) \\
\hline R124C/G470Ter & FAS1-1/FAS1-3 & LCD1 & Eighth & (Sakimoto et al., 2003) \\
\hline $\mathrm{R} 124 \mathrm{C} / \mathrm{A} 546 \mathrm{D}$ & FAS1-1/FAS1-4 & Variant LCD & Second - Third & (Cao et al., 2017) \\
\hline $\mathrm{R} 124 \mathrm{H}$ & FAS1-1 & GCD2 & First - Fourth & (Munier et al., 1997) \\
\hline R124H/P130Ter & FAS1-1 & GCD2 & Third & (Yam et al., 2012) \\
\hline R124H/R179Ter & FAS1-1 & GCD2 & Fourth & (Song et al., 2015) \\
\hline $\mathrm{R} 124 \mathrm{H} / \mathrm{N} 544 \mathrm{~S}$ & FAS1-1/FAS1-4 & GCD2-LCD & Seventh & (Yamada et al., 2009) \\
\hline R124L & FAS1-1 & $\mathrm{RBCD}$ & First - Second & (Okada et al., 1998) \\
\hline R124L/T125- & FAS1-1 & Atypical GCD & First & (Dighiero et al., 2000a) \\
\hline R124S & FAS1-1 & GCD1 & Fifth & (Stewart et al., 1999b) \\
\hline E131D & FAS1-1 & Unknown & Third & (Foja et al., 2016) \\
\hline R496W & FAS1-3 & LCD4 & Ninth & (Kawasaki et al., 2011) \\
\hline \multirow[t]{2}{*}{ P501T } & Linker region & LCD3a & Eighth - Ninth & (Yamamoto et al., 1998) \\
\hline & FAS1-3/FAS1-4 & & & \\
\hline M502V & FAS1-4 & Unknown & Fourth & (Zenteno et al., 2009) \\
\hline M502V/R555Q & FAS1-4 & Atypical TBCD & First & (Niel-Butschi et al., 2011) \\
\hline V505D & FAS1-4 & LCD1 & Third & (Tian et al., 2005) \\
\hline L509P & FAS1-4 & GCD2 / LCD1 & Third & (Gruenauer-Kloevekorn et al., 2009) \\
\hline L509R & FAS1-4 & Atypical LCD & Third - Fourth & (Niel-Butschi et al., 2011) \\
\hline R514P/F515L & FAS1-4 & LCD1 & Second & (Zhong et al., 2010) \\
\hline S516R & FAS1-4 & Atypical GCD1 & Second & (Paliwal et al., 2010) \\
\hline L518P & FAS1-4 & LCD1 & Second & (Endo et al., 1999) \\
\hline L518R & FAS1-4 & $\mathrm{LCD} 1 / 3 \mathrm{a}$ & Fifth & (Munier et al., 2002) \\
\hline V519delinsGG & FAS1-4 & $\mathrm{RBCD}$ & First - Second & (Kheir et al., 2019) \\
\hline I522N & FAS1-4 & LCD1 & Second & (Zhang et al., 2009a) \\
\hline L527R & FAS1-4 & LCD4 & Sixth - Seventh & (Fujiki et al., 1998) \\
\hline T538P & FAS1-4 & LCD1 & Third & (Yu et al., 2006) \\
\hline T538R & FAS1-4 & $\mathrm{LCD} 1 / 3 \mathrm{a}$ & Second & (Munier et al., 2002) \\
\hline V539D & FAS1-4 & LCD1 & Unknown & (Chakravarthi et al., 2005) \\
\hline F540S & FAS1-4 & LCD3a & Fifth & (Stix et al., 2005) \\
\hline
\end{tabular}




\begin{tabular}{|c|c|c|c|c|}
\hline F540del & FAS1-4 & $\mathrm{RBCD} / \mathrm{LCD} 1 / 3 \mathrm{a}$ & Unknown & (Rozzo et al., 1998) \\
\hline P542R & FAS1-4 & Variant LCD & Sixth & (Cho et al., 2012) \\
\hline N544S & FAS1-4 & Variant LCD & Seventh & (Mashima et al., 2000) \\
\hline A546D & FAS1-4 & Atypical LCD & Third - Fourth & (Eifrig et al., 2004) \\
\hline A546D/P551Q & FAS1-4 & LCD1 & Fourth & (Klintworth et al., 2004) \\
\hline A546T & FAS1-4 & LCD3a & Fourth & (Dighiero et al., 2000b) \\
\hline F547C & FAS1-4 & GCD & Seventh & (Foja et al., 2016) \\
\hline F547S & FAS1-4 & Variant LCD & Fifth & (Takacs et al., 2007) \\
\hline R548P & FAS1-4 & Variant LCD & Seventh & (Chae et al., 2016) \\
\hline A549T/R555W & FAS1-4 & GCD1 & First & (Frising et al., 2006) \\
\hline L550P & FAS1-4 & GCD2 & Unknown & (Zenteno et al., 2009) \\
\hline L550P/H626R & FAS1-4 & Atypical GCD & Unknown & (Zenteno et al., 2009) \\
\hline R555Q & FAS1-4 & TBCD & First - Second & (Munier et al., 1997) \\
\hline R555W & FAS1-4 & GCD1 & First - Second & (Munier et al., 1997) \\
\hline L558P & FAS1-4 & Atypical LCD & Fifth - Sixth & (Pampukha et al., 2009) \\
\hline L558R & FAS1-4 & Variant LCD & Sixth & (Dudakova et al., 2016) \\
\hline L559V & FAS1-4 & Atypical GCD & Fifth & (Paliwal et al., 2010) \\
\hline L565H & FAS1-4 & Variant LCD & Unknown & (Zhang et al., 2019) \\
\hline L565P & FAS1-4 & Variant LCD & Sixth & (Oldak et al., 2014) \\
\hline L569Q & FAS1-4 & Variant LCD & Sixth & (Song et al., 2015) \\
\hline L569R & FAS1-4 & LCD1 & First & (Warren et al., 2003) \\
\hline $\mathrm{H} 572 \mathrm{R}$ & FAS1-4 & LCD1 & Fourth & (Atchaneeyasakul et al., 2006) \\
\hline H572del & FAS1-4 & Variant LCD & Seventh & (Aldave et al., 2006) \\
\hline G594V & FAS1-4 & LCD4 & Sixth - Seventh & (Chakravarthi et al., 2005) \\
\hline V613G & FAS1-4 & Variant LCD & Seventh & (Niel-Butschi et al., 2011) \\
\hline V613-P616del & FAS1-4 & Variant LCD & Unknown & (Yang et al., 2010) \\
\hline M619K & FAS1-4 & Variant GCD2 & Fifth - Sixth & (Aldave et al., 2008) \\
\hline A620D & FAS1-4 & LCD1/3a & Fourth & (Lakshminarayanan et al., 2011) \\
\hline A620P & FAS1-4 & LCD3a & Fourth - Sixth & (Jung et al., 2014) \\
\hline T621P & FAS1-4 & LCD3a & Fifth & (Song et al., 2015) \\
\hline $\mathrm{N} 622 \mathrm{H}$ & FAS1-4 & LCD1/3a & Fifth & (Stewart et al., 1999a) \\
\hline N622K & FAS1-4 & LCD3a & Fourth - Fifth & (Munier et al., 2002) \\
\hline G623D & FAS1-4 & $\mathrm{RBCD} / \mathrm{LCD}$ & Sixth - Seventh & (Afshari et al., 2001) \\
\hline G623R & FAS1-4 & Variant LCD & Third - Fifth & (Gruenauer-Kloevekorn et al., 2009) \\
\hline V624M & FAS1-4 & Atypical LCD & Fifth & (Afshari et al., 2008) \\
\hline V624-V625del & FAS1-4 & Atypical LCD & Third & (Chakravarthi et al., 2005) \\
\hline V625D & FAS1-4 & LCD1 & Second & (Tian et al., 2007) \\
\hline H626P & FAS1-4 & RBCD-TBCD / & First - Second & (Munier et al., 2002) \\
\hline
\end{tabular}




$\begin{array}{lllll}\text { H626R } & \text { FAS1-4 } & \text { LCD1/3a } & \text { Third }- \text { Fifth } & \text { (Stewart et al., 1999a) } \\ \text { V627Sfs*44 } & \text { FAS1-4 } & \text { LCD3a } & \text { Fourth }- \text { Fifth } & \text { (Munier et al., 2002) } \\ \text { T629insNVP } & \text { FAS1-4 } & \text { LCD1/3a } & \text { Second } & \text { (Schmitt-Bernard et al., 2000b) } \\ \text { V631D } & \text { FAS1-4 } & \text { Variant LCD } & \text { Fifth } & \text { (Munier et al., 2002) }\end{array}$

${ }^{1}$ TGFBIp domains from UniProt, accession no. Q15582: CROPT (45-99), FAS1-1 (103-236), FAS1-2 (240-371), FAS1-3 (375-498), FAS1-4 (502-632). ${ }^{2}$ GCD, granular corneal dystrophy; LCD, lattice corneal dystrophy variants; RBCD, ReisBücklers corneal dystrophy; and TBCD, Thiel-Behnke corneal dystrophy. 
Table 3.

Patient cases subjected to protein profiling of deposited material.

\begin{tabular}{llll}
\hline Mutation & Protein domain & Phenotype & Reference \\
\hline R124C & FAS1-1 & LCD1 & (Courtney et al., 2015; Venkatraman et al., 2017) \\
R124H & FAS1-1 & GCD2 & (Karring et al., 2012; Poulsen et al., 2016) \\
A546D & FAS1-4 & Atypical LCD & (Karring et al., 2013) \\
A546D/P551Q & FAS1-4 & LCD1 & (Poulsen et al., 2014b) \\
R555W & FAS1-4 & GCD1 & (Courtney et al., 2015) \\
V624M & FAS1-4 & Atypical LCD & (Karring et al., 2012) \\
H626R & FAS1-4 & LCD1/3a & (Venkatraman et al., 2017) \\
\hline
\end{tabular}


Table 4.

TGFBI mouse models.

\begin{tabular}{|c|c|c|}
\hline Type & Phenotype & Reference \\
\hline \multirow[t]{2}{*}{ Knockout } & Spontaneous tumor development & (Zhang et al., 2009b) \\
\hline & Reduced bone size & (Yu et al., 2012) \\
\hline \multirow[t]{2}{*}{ Knockout } & Abnormal lung morphology & (Ahlfeld et al., 2016) \\
\hline & Normal corneal structure & (Poulsen et al., 2018) \\
\hline \multirow[t]{2}{*}{ Knockout } & Vascular inflammatory response & (Bae et al., 2014) \\
\hline & Reduced skeletal size & (Lee et al., 2015) \\
\hline Knockout & Increased diabetes risk & (Han et al., 2014) \\
\hline Overexpression (liver) & Anterior segment dysgenesis & (Kim et al., 2007) \\
\hline Overexpression & Corneal opacities & (Liao et al., 2013) \\
\hline R555W mutant (overexpressed) & Retinal degeneration & (Bustamante et al., 2008) \\
\hline R124H mutant & Corneal opacities & (Yamazoe et al., 2015) \\
\hline
\end{tabular}


Fig. 1. Schematic representation and three-dimensional structure of TGFBIp. A, The secreted form of TGFBIp (residues 24-683) constitutes an N-terminal CROPT domain followed by four FAS1 domains. TGFBIp has three intradomain disulfide bridges between C49 and C85 (CROPT), C84 and C97 (CROPT), and C473 and C478 (FAS1-3). Two interdomain disulfide bridges are located between C74 (CROPT) and C339 (FAS1-2) and C214 (FAS1-1) and C317 (FAS1-2). C65 is not engaged in any intramolecular disulfide bridge. The C-terminus contains an RGD binding motif and a truncation site at residue A657. B, Ribbon plot of TGFBIp (residues 43-637) with CROPT in magenta, FAS1-1 in cyan, FAS1-2 in blue, FAS1-3 in green, and FAS1-4 in orange. The disulfide bridges and the unbound C65 are depicted as yellow sticks. Due to the high flexibility of the N-terminus and C-terminus of TGFBIp, the structure of these regions could not be determined.

Fig. 2. A, Slit-lamp photograph of a 45-year-old male GCD1 patient. B, A 48-year-old female LCD patient. C, GCD2 cornea from a 32-year-old male patient 8 years after LASIK treatment. A genetic test revealed a heterozygous TGFBI R124H mutation.

Fig. 3. World map of reported cases with various TGFBI mutations. Each bubble placed over a region or country contains the reported case information, such as ethnicities, mutations, and case numbers. The map illustrates that TGFBI mutation cases are reported all over the world, except in regions with limited research capacity or language difficulties for publication. Very few cases were reported from South America, and no case reports were identified from Africa or Russia (Chao-Shern et al., 2019).

Fig. 4. Tissue-specific processing of human TGFBIp in cornea, skin, plasma, and platelets. Human specimen samples were subjected to two-dimensional gel electrophoresis, followed by immunoblotting against TGFBIp. Differential processing was observed across the different tissue samples supportive of tissue-specific processing. Upper and lower blots are biological duplicates. Tissues were handled and analyzed as described in (Poulsen et al., 2019).

Fig. 5. Schematic representation of possible aggregation mechanisms involved in TGFBI-linked corneal dystrophies associated with mutations in the FAS1-4 domain (red X). A, TGFBIp undergoes extensive $\mathrm{N}$-terminal processing by the proteolytic machinery in the cornea, leading to FAS1-4-containing products, which are subsequently cleared. B, Several mechanisms might lead to GCD and TBCD where intact or near-intact TGFBIp accumulates. Bioinformatics analysis has shown reduced solubility of the folded monomeric state of the FAS1-4 domain for some of the mutants. Destabilization can lead to aggregates through hydrophobic collapse. Abnormal turnover due to resistance to proteolytic degradation and/or changes in the interactions with the ECM or integrins might result in a higher 
concentration of soluble TGFBIp leading to increased aggregation. C, In LCD, fragments of TGFBIp seem to accumulate. Mutations in FAS1-4 destabilize the structure of TGFBIp, which might cause the FAS1-4 domain to fibrillate directly and/or lead to a change in its proteolytic turnover by the serine protease HtrA1, which liberates amyloidogenic regions of the FAS1-4 domain. Sulfated GAGs might promote the fibrillation of LCD mutants. 
Figure 1
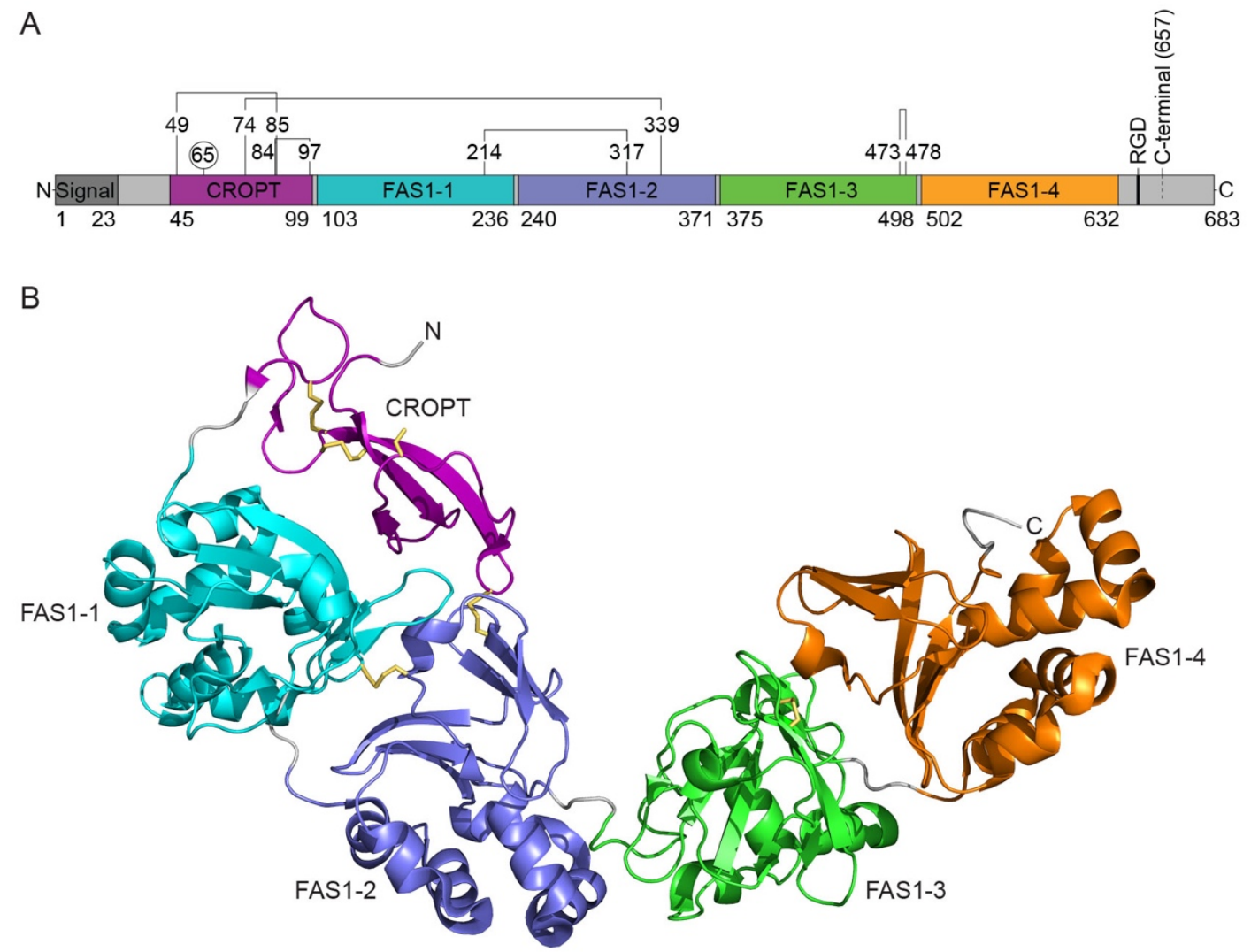
Figure 2

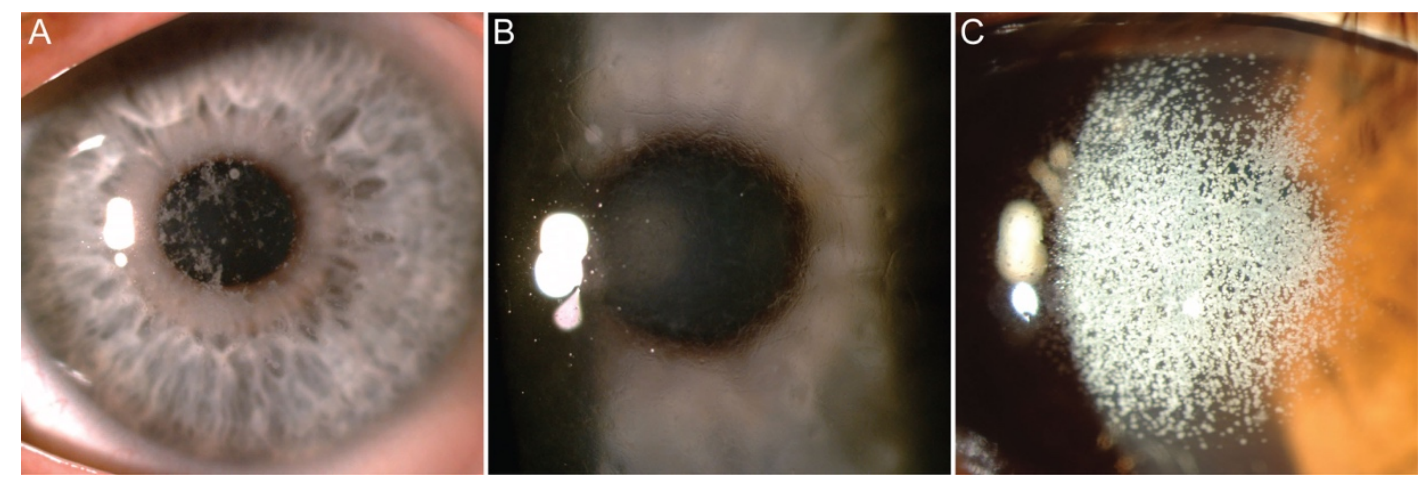


Figure 3

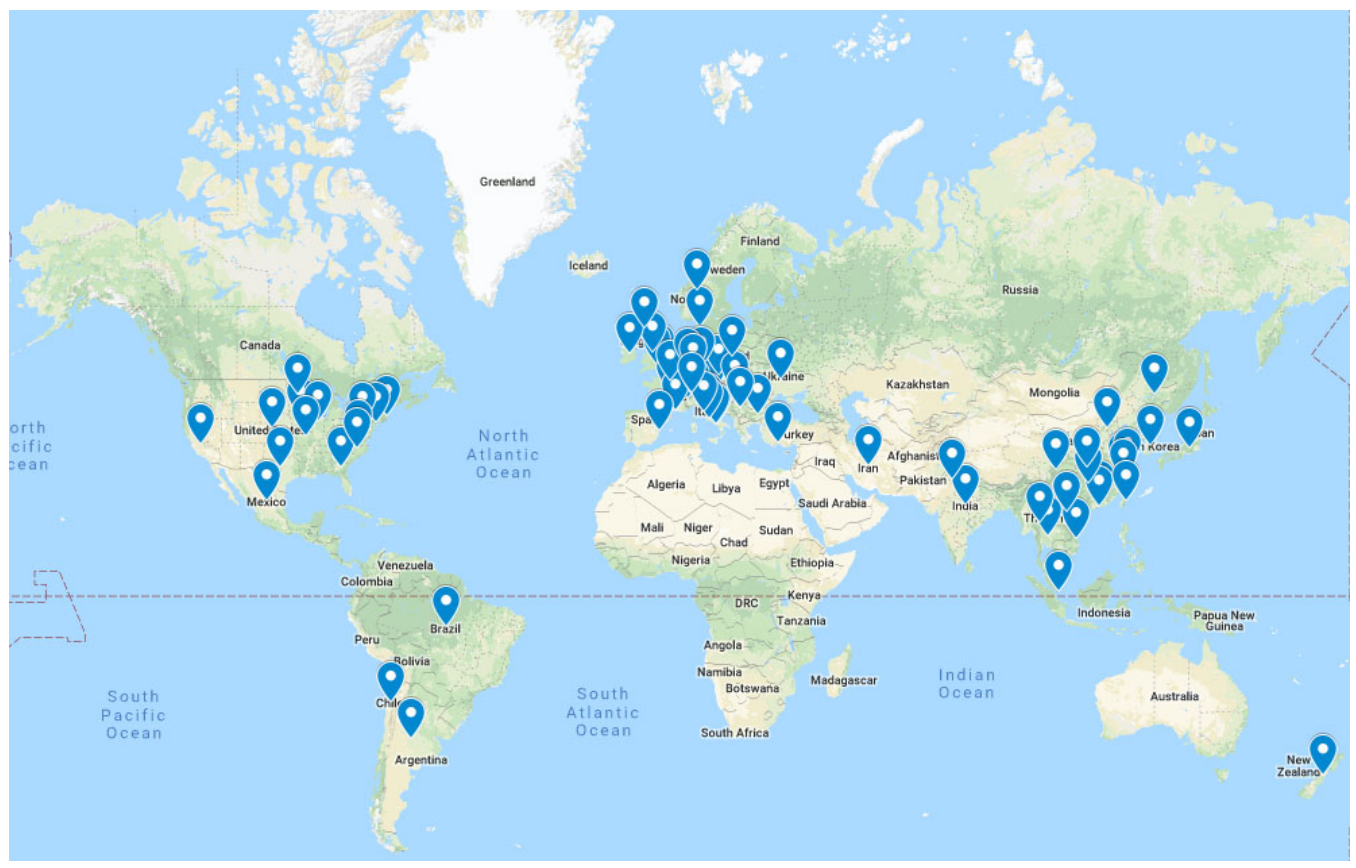


Figure 4

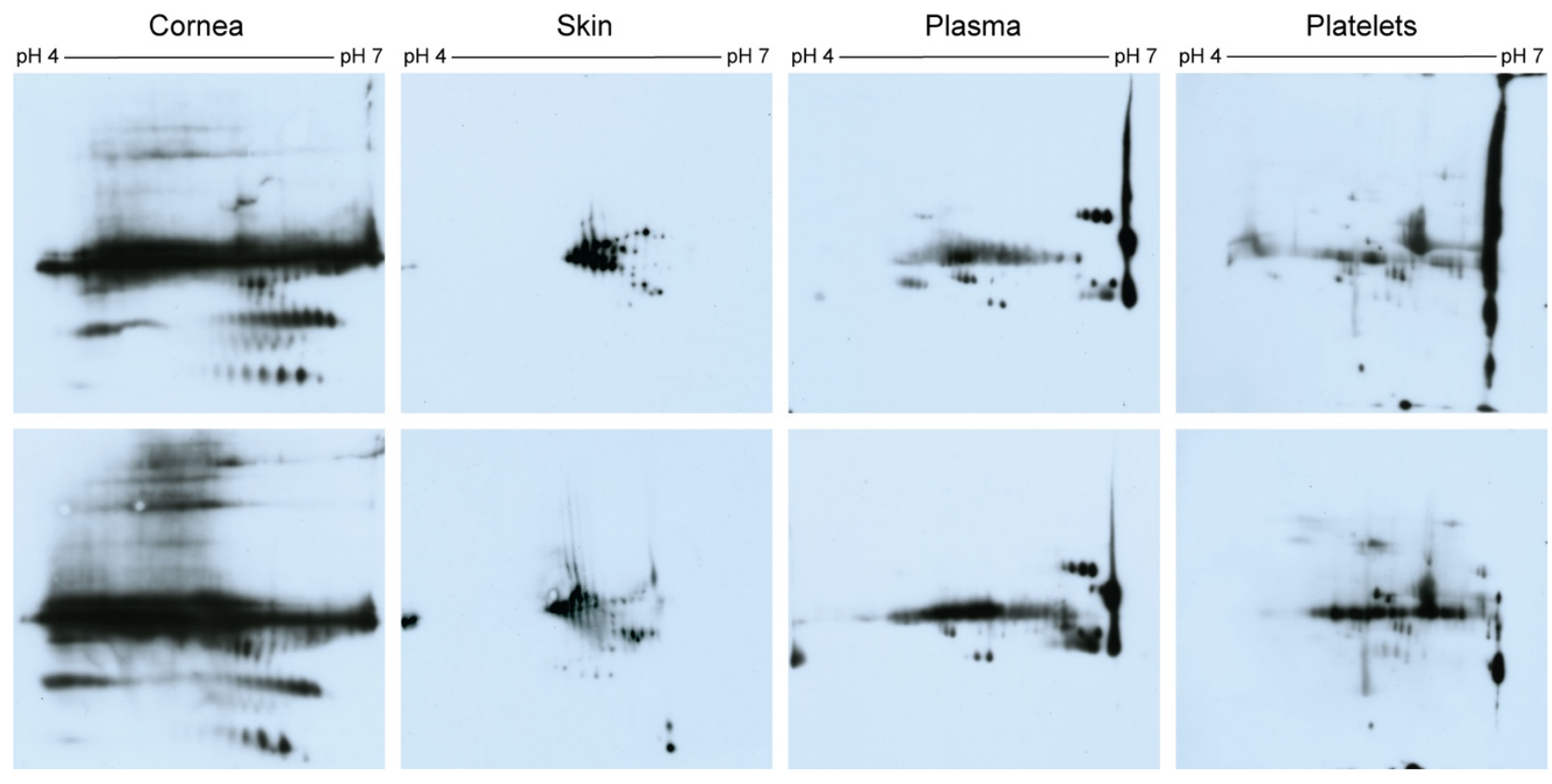


Figure 5

A. Normal TGFBIp turnover

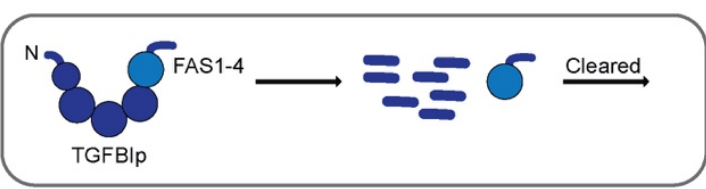

B. Granular Corneal Dystrophy and Thiel-Behnke Corneal dystrophy

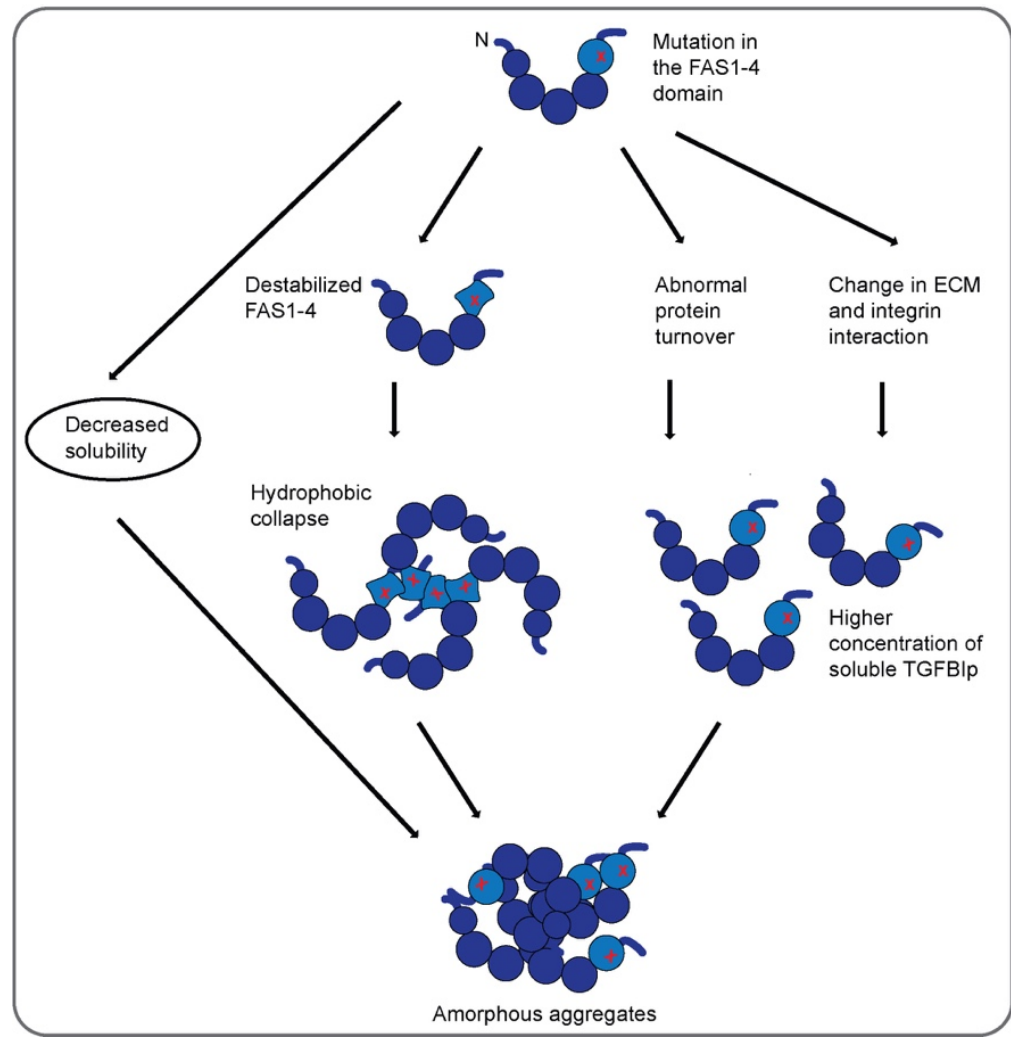

\section{Lattice Corneal Dystrophy}

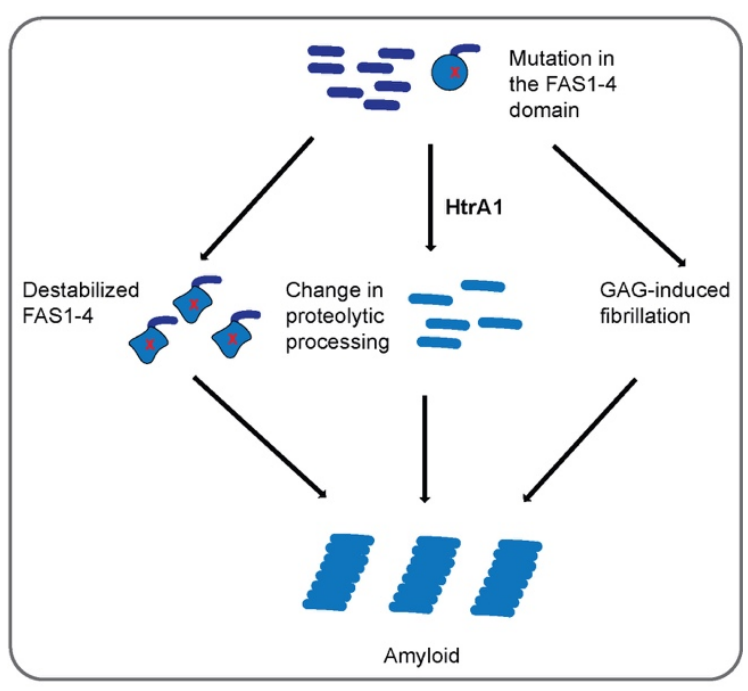

